Some Historical

Perspectives on the

Bond-Stock Yield Model

for Crash Prediction

around the World

Sebastien Lleo

William T. Ziemba

SRC Discussion Paper No 21

September 2014

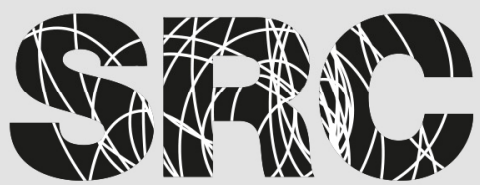




\begin{abstract}
We provide a historical perspective focusing on Ziemba's experiences and research on the bond-stock earnings yield differential model (BSEYD) starting from when he first used it in Japan in 1988 through to the present in 2014. The model has called many but not all crashes. Those called have high interest rates in long term bonds relative to the trailing earnings to price ratio. In general, when the model is in the danger zone, almost always there will be a crash. The model predicted the crashes in China, Iceland and the US in the 2006-9 period. Iceland had a drop of fully $95 \%$. For the US the call was on June 14, 2007 and the stock market fell 56.8\%. A longer term study for the US, Canada, Japan, Germany, and UK shows that over long periods being in the stock market when the bond-stock signal is not in the danger zone and in cash when it is in the danger zone provides a final wealth about double buy and hold for each of these five countries. The best use of the model is for predicting crashes. Finally we compare Shiller's high PE ratio crash model to the BSEYD model for the US market from 19622012. While both models add value, the BSEYD model predicts crashes better.
\end{abstract}

Keywords: stock market crashes, BSEYD and Fed models, long term investing

JEL classification: G10, G11, G12, G14, G15

This paper is published as part of the Systemic Risk Centre's Discussion Paper Series. The support of the Economic and Social Research Council (ESRC) in funding the SRC is gratefully acknowledged [grant number ES/K002309/1].

Sebastien Lleo, Finance Department and Behavioral Sciences Research Center, NEOMA Business School

William T. Ziemba, Alumni Professor of Financial Modeling and Stochastic Optimization (Emeritus), University of British Columbia, Vancouver, BC and Distinguished Visiting Scholar, Systemic Risk Centre, London School of Economics, and Visiting Professor at Sabanci University, Turkey, and the Korean Institute for Advanced Study in Science and Technology, Korea

Published by

Systemic Risk Centre

The London School of Economics and Political Science

Houghton Street

London WC2A 2AE

All rights reserved. No part of this publication may be reproduced, stored in a retrieval system or transmitted in any form or by any means without the prior permission in writing of the publisher nor be issued to the public or circulated in any form other than that in which it is published.

Requests for permission to reproduce any article or part of the Working Paper should be sent to the editor at the above address.

(c) Sebastien Lleo, William T. Ziemba submitted 2014 


\title{
Some historical perspectives on the Bond-Stock Earnings Yield Model for crash prediction around the world
}

\author{
Sebastien Lleo $^{\dagger}$ and William T. Ziemba \\ ${ }^{\dagger}$ Finance Department and Value and Persuasion Research Pole, NEOMA Business \\ School, email: sebastien.lleo@NEOMA-bs.fr, \\ ${ }^{\ddagger}$ Alumni Professor of Financial Modeling and Stochastic Optimization (Emeritus), \\ University of British Columbia, Vancouver, BC; Visiting Professor Korean \\ Advanced Institute for Science and Technology and Sabanci University, Turkey, \\ and Distinguished Visiting Research Associate, Systemic Risk Centre, London \\ School of Economics, email: wtzimi@mac.com
}

May 17, 2014

\begin{abstract}
We provide a historical perspective focusing on Ziemba's experiences and research on the bond-stock earnings yield differential model (BSEYD) starting from when he first used it in Japan in 1988 through to the present in 2014. The model has called many but not all crashes. Those called have high interest rates in long term bonds relative to the trailing earnings to price ratio. In general, when the model is in the danger zone, almost always there will be a crash. The model predicted the crashes in China, Iceland and the US in the 2006-9 period. Iceland had a drop of fully $95 \%$. For the US the call was on June 14, 2007 and the stock market fell 56.8\%. A longer term study for the US, Canada, Japan, Germany, and UK shows that over long periods being in the stock market when the bond-stock signal is not in the danger zone and in cash when it is in the danger zone provides a final wealth about double buy and hold for each of these five countries. The best use of the model is for predicting crashes. Finally we compare Shiller's high PE ratio crash model to the BSEYD model for the US market from 1962-2012. While both models add value, the BSEYD model predicts crashes better.
\end{abstract}

Keywords: stock market crashes, BSEYD and Fed models, long term investing JEL codes: G10, G11, G12, G14, G15 


\section{Introduction}

Since credit for the first publications on the BSEYD and its relationship to the later discovered and widely discussed Fed model has eluded Ziemba, he would like to discuss his early experiences with the model and the historical record of his involvement with it since 1988. The Fed model is a special case of the BSEYD model. ${ }^{1}$

\section{A bond-stock return crash danger model $^{2}$}

In May 1988 I was invited by Yamaichi Securities to interview to be the first Yamaichi visiting professor of finance at the University of Tsukuba, a Japanese national university. Yamaichi wished to try to establish the study of finance, especially investments, in Japanese universities, which was not generally taught. They established a five-year program with five such visiting professors in succession. The teaching at the university (I taught investments, security market anomalies, futures and options) was supplemented with a two-day a week consulting position in Tokyo some 60 kilometers southwest of Tsukuba at Yamaichi Securities then the fourth largest securities firm in Japan and the sixth largest in the world. In my interview I asked if I could study market imperfections (anomalies) and stock market crashes in two study groups with some of the young Yamaichi Research Institute employees who also came up to Tsukuba for my classes.

My proposal was accepted and each study group with about ten eager young students in each group proceeded by me giving lectures on the US experience and they helping me investigate the Japanese situation. We focused on the postwar period 1948 to 1988 and much of what I learned appears in the book Invest Japan, Ziemba and Schwartz (1991) and the 1989-1993 research papers of Ziemba and Schwartz and Stone and Ziemba (1993). My wife Dr Sandra L. Schwartz and I also wrote the book Power Japan (1992) that discussed the Japanese economy. Sandra had a pretty good idea right away that the Japanese policies that let to astronomically high land and stock prices and massive trade surpluses would lead to disaster and they would eventually lose most of the money that they received from selling cars, stereos and the like. We made a list of prestige buildings that the Japanese overpaid for in the 1987-89 era in Power Japan. Even at the height of their economic power in 1989 only $3 \%$ of Japanese assets were invested abroad.

My study groups started in August 1988 and ended a year later. I was asked to remain as a

\footnotetext{
${ }^{1}$ This paper presents one crash prediction model that has worked well over time in the US, Japan and elsewhere. Other crash prediction models are discussed by Sornette and Zhou (2002), Sornette (2009), and Yan, Woodard and Sornette (2012ab). Jarrow, Kohia and Protter (2011) discuss when a bubble exists. Shireyev, Zhitlukhin and Ziemba (2014ab) discuss stopping rule model to exit and enter bubble type markets.

${ }^{2}$ This section relates to Ziemba's early experience with this model so it is written in his words.
} 
consultant for the fall of 1988 to complete a factor model discussed in Schwartz and Ziemba (2000) which was originally presented at a Berkeley Program in Finance meeting in Santa Barbara in September 1992. The factor model used anomaly ideas such as mean reversion, earnings surprise, momentum, price-earnings ratios, future earnings over price, and value embedded in 30 variables to separate and rank stocks by their future mean performance from best to worst for all the stocks on the Tokyo Stock Exchange first section which was about $86 \%$ of the total capitalization. The model motivated by a similar model for the US by Jacobs and Levy (1988), was estimated yearly but updated monthly. The model performed well out of sample so was useful for hedge fund long-short trading as well as long only investing. The hedge fund Buchanan Partners in London discovered the model which was discussed in Invest Japan when they bought the book and hired me to help them in their Japanese warrant trading which was largely long underpriced warrants and short overpriced stocks. Their trading was successful and the model, which was estimated using data during a stock market rise still worked when the decline came since variables such as earnings were the key drivers of the returns. An update of Japanese anomalies to 1994 appears in Comolli and Ziemba (2000).

In the crash study group I came up with a simple model in 1988 with only a single variable that being the difference between stock and bond rates of return. ${ }^{3}$ The idea was that stocks and bonds compete for investment dollars and, when interest rates are low, stocks are favored and when interest rates are high, bonds are favored. The main thing that I wished to focus on is that when the measure, the difference between these two rates, the long bond yield minus the earnings yield (the reciprocal of the price earnings ratio), was very large, then there was a high chance of a stock market crash. A crash was defined as a $10 \%$ fall in the index within one year. The model explains the October $1987 \mathrm{crash}$. That application is how this idea came to me. Table 1 and Figure 1 show this. The boxes indicate that there is extreme danger in the stock market because 30-year government bond yields are very much higher than usual stock market yields measured by the reciprocal of the previous year's reported price earnings ratio. These high interest rates invariably lead to a stock market crash. Here the danger indicator moved across a statistical $95 \%$ confidence line in April. The market ignored this signal but did eventually crash in October 1987. There was a similar signal ignored by most investors in the US S\&P500 around April 1999 and then a crash that began in August 2000 and a weak stock market in 2001/02 which is discussed below.

Returning to the story in Japan, in 1988-89, I asked one of my young colleagues in my crash study group, Sugheri Iishi, to check the accuracy of the bond-stock prediction model in Japan. We found that there were twenty $10 \%$ plus crashes during the out of sample forty years, 1949-89. Whenever this measure was in the danger zone (that is outside a $95 \%$

\footnotetext{
${ }^{3}$ Later we show that this difference model is a generalization of the ratio model, known as the Fed model. Koivu, Pennanen and Ziemba (2005) study this model which seems to date from Fed minutes in 1996. See Yardeni (1997).
} 
Table 1: S\&P500 index, PE ratios, government bond yields and the yield premium over stocks, January 1984 to August 1988. Source: Ziemba and Schwartz (1991)

\begin{tabular}{|c|c|c|c|c|c|c|}
\hline & \multicolumn{3}{|c|}{$\mathrm{S} \& \mathrm{P}$} & \multicolumn{3}{|c|}{ (b) } \\
\hline & & Index & PER & 30 Yr G bd & $1 / \mathrm{pe}, \%$ & (a)-(b) \\
\hline \multirow[t]{12}{*}{1986} & Jan & 208.19 & 14.63 & 9.32 & 6.84 & 2.48 \\
\hline & Feb & 219.37 & 15.67 & 8.28 & 6.38 & 1.90 \\
\hline & Mar & 232.33 & 16.50 & 7.59 & 6.06 & 1.53 \\
\hline & Apr & 237.98 & 16.27 & 7.58 & 6.15 & 1.43 \\
\hline & May & 238.46 & 17.03 & 7.76 & 5.87 & 1.89 \\
\hline & Jun & 245.30 & 17.32 & 7.27 & 5.77 & 1.50 \\
\hline & Jul & 240.18 & 16.31 & 7.42 & 6.13 & 1.29 \\
\hline & Aug & 245.00 & 17.47 & 7.26 & 5.72 & 1.54 \\
\hline & Sep & 238.27 & 15.98 & 7.64 & 6.26 & 1.38 \\
\hline & Oct & 237.36 & 16.85 & 7.61 & 5.93 & 1.68 \\
\hline & Nov & 245.09 & 16.99 & 7.40 & 5.89 & 1.51 \\
\hline & Dec & 248.60 & 16.72 & 7.33 & 5.98 & 1.35 \\
\hline \multirow[t]{12}{*}{1987} & Jan & 264.51 & 15.42 & 7.47 & 6.49 & 0.98 \\
\hline & Feb & 280.93 & 15.98 & 7.46 & 6.26 & 1.20 \\
\hline & Mar & 292.47 & 16.41 & 7.65 & 6.09 & 1.56 \\
\hline & Apr & 289.32 & 16.22 & 9.56 & 6.17 & 3.39 \\
\hline & May & 289.12 & 16.32 & 8.63 & 6.13 & 2.50 \\
\hline & Jun & 301.38 & 17.10 & 8.40 & 5.85 & 2.55 \\
\hline & Jul & 310.09 & 17.92 & 8.89 & 5.58 & 3.31 \\
\hline & Aug & 329.36 & 18.55 & 9.17 & 5.39 & 3.78 \\
\hline & Sep & 318.66 & 18.10 & 9.66 & 5.52 & 4.14 \\
\hline & Oct & 280.16 & 14.16 & 9.03 & 7.06 & 1.97 \\
\hline & Nov & 245.01 & 13.78 & 8.90 & 7.26 & 1.64 \\
\hline & Dec & 240.96 & 13.55 & 9.10 & 7.38 & 1.72 \\
\hline \multirow[t]{8}{*}{1988} & Jan & 250.48 & 12.81 & 8.40 & 7.81 & 0.59 \\
\hline & Feb & 258.10 & 13.02 & 8.33 & 7.68 & 0.65 \\
\hline & Mar & 265.74 & 13.42 & 8.74 & 7.45 & 1.29 \\
\hline & Apr & 262.61 & 13.24 & 9.10 & 7.55 & 1.55 \\
\hline & May & 256.20 & 12.92 & 9.24 & 7.74 & 1.50 \\
\hline & Jun & 270.68 & 13.65 & 8.85 & 7.33 & 1.52 \\
\hline & Jul & 269.44 & 13.59 & 9.18 & 7.36 & 1.82 \\
\hline & Aug & 263.73 & 13.30 & 9.30 & 7.52 & 1.78 \\
\hline
\end{tabular}

confidence band), there was a crash of $10 \%$ or more from the current level within one year. This was 12 out of 12, a splendid prediction record. Not all crashes had the measure in the danger zone but whenever it was there was a crash with no misses. Some eight crashes occurred for other reasons. Reinhart and Rogoff (2009) in their study of banking crises study some such circumstances that lead to stock market crashes of both interest rate and non-interest rate driven types. See also the classic book Kindleberger and Aliber (2011) and our study of hedge fund and related disasters. Lleo and Ziemba (2014a) study hedge funds and bank trading disasters, how they occur and how they could be prevented. 
Figure 1: Bond and stock yield differential model for NSA, 1980-1990, Source: Ziemba and Schwartz, 1991

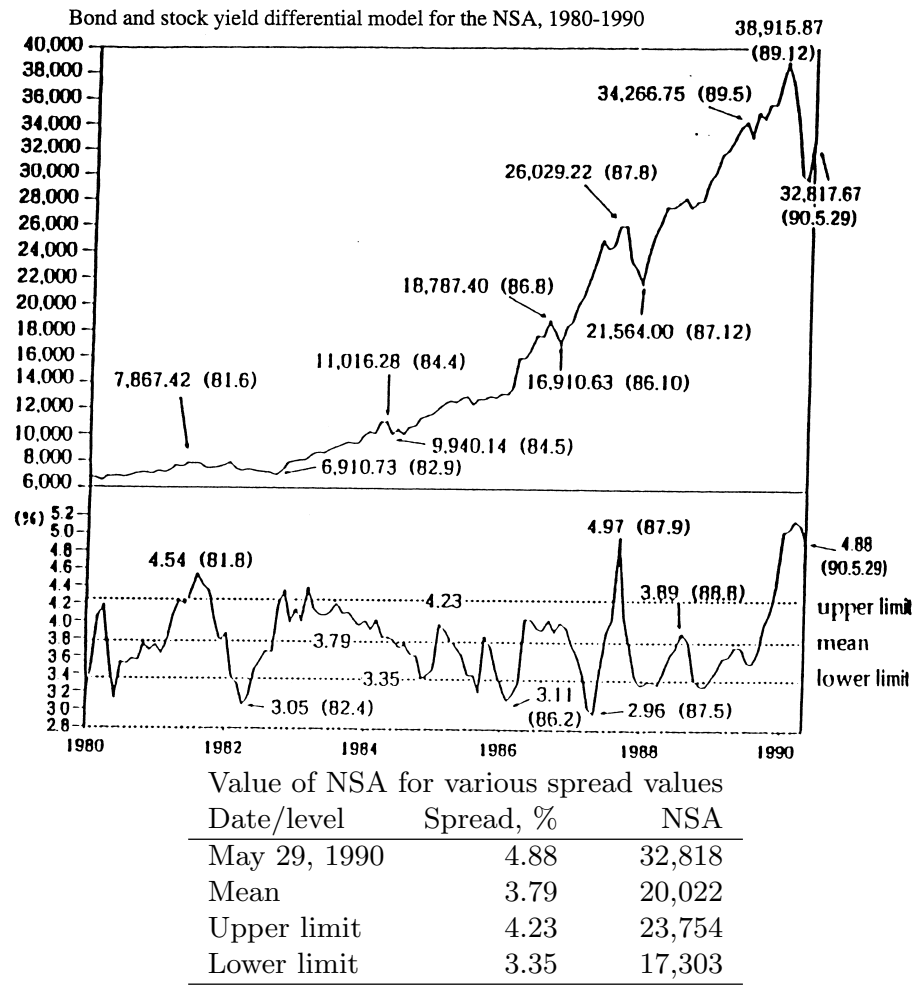

So the measure was successful at predicting future crashes - but when and how deep there was no precise way to know. However, long-run mean reversion suggests that the longer the bull run is and the more over-priced the measure is, the longer and deeper the decline will probably be. Then one can use the measure as part of an econometric system to estimate future scenarios.

Each time the spread exceeded the 4.23 cutoff (which was higher than $95 \%$ confidence) there was a crash. The measure was way in the danger zone in late 1989 and the decline (the 21st crash) began on the first trading day of 1990 with the Nikkei stock average peaking at 38,916 . See Figure 1. It is too bad Yamaichi's top management did not listen to Iishi when I sent him up to explain our results in Japanese; there was much greater danger in the market then they thought in 1989. By 1995 Yamaichi Securities was bankrupt and ceased to exist.

The model also indicates that the valuation was still high as of May 29, 1990 at 4.88. Not much later, the $22 \mathrm{nd}$ crash began. Interestingly, at the bottom of the $22 \mathrm{nd}$ crash on 
October 1, 1990, the NSA was at 20,222, which was almost exactly the mean. Meanwhile, the same calculation on May 29, 1990, for the S\&P500 is shown in Figure 2. Indeed, it was cheap, that is below the mean, since the September 1987 peak of 4.42. The May 29, 1990 value of 1.11 was, however, slightly above the mean level and the highest since the late fall of 1987.

Figure 2: Bond and stock yield differential model for the S\&P500, 1980-1990, Source: Ziemba and Schwartz, 1991

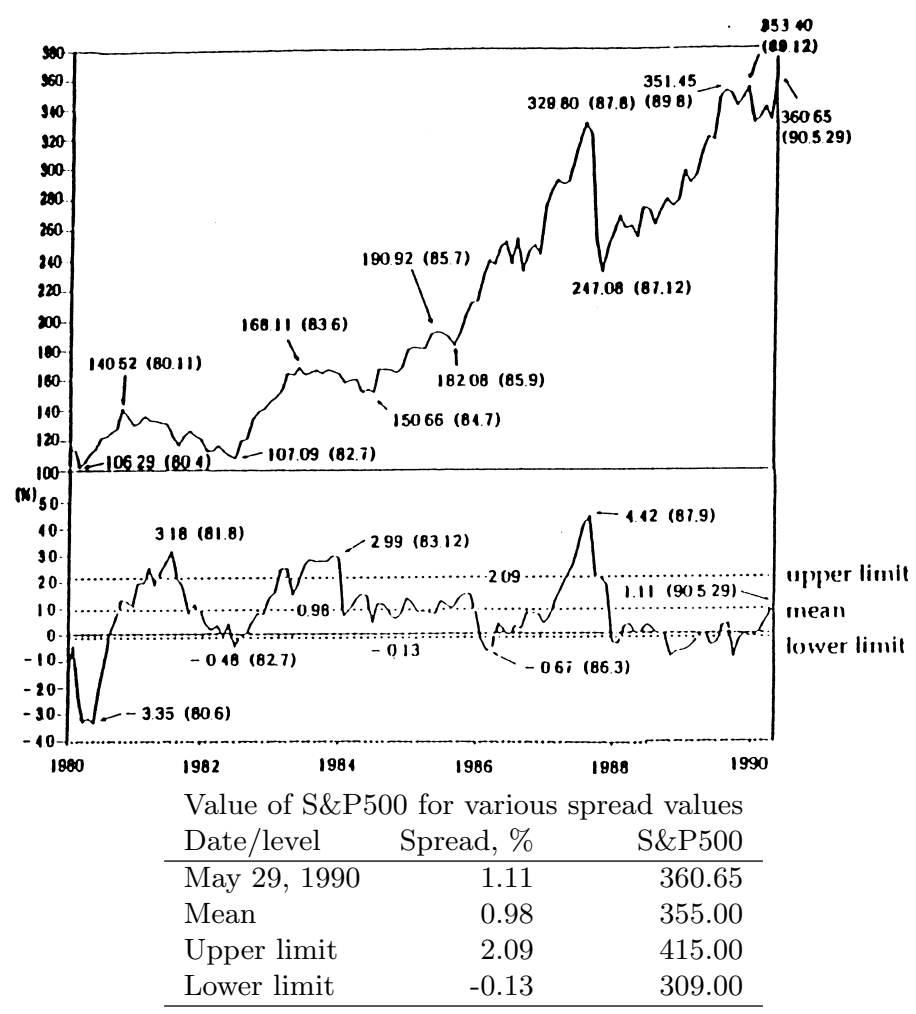

Japan has had weak stock and land markets for twenty years, since the beginning of 1990 . There are many factors for this that are political as well as economic. But the rising interest rates for eight full months until August 1990, see Figure 3(a) is one of them. This extreme tightening of an over-levered economy was too much. Cheap and easily available money, which caused the big run-up in asset prices in the 1980s turned into expensive and unavailable money in the 1990s. This has parallels to the 2007-2009 US situation where easy available money, not necessarily cheap, turned into unavailable cheap money.

Despite the terrible earthquake and tsunami in Japan in March 2011, many analysts con- 


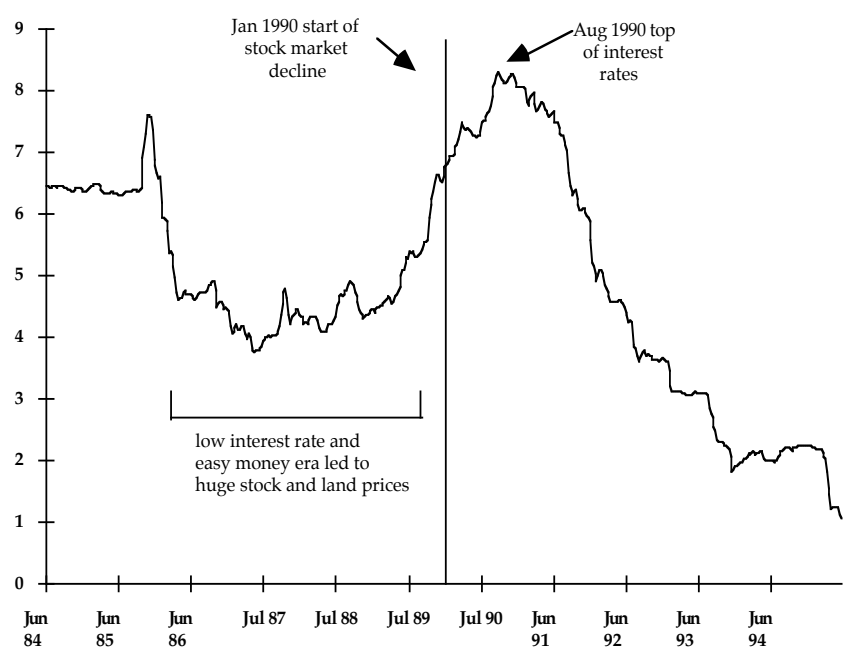

(a) Short term interest rates in Japan, June 1984 to June 1995

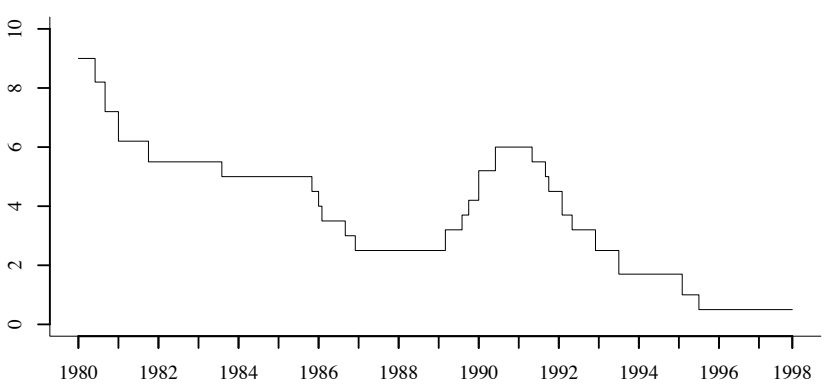

(b) Bank of Japan target interest rates 1980 to 1998

Figure 3: Interest rates in Japan

sider the stock market finally a buy because of very low valuations. They are proved right in 2013 with a large rally caused more by a lower yen than high earnings or low interest rates. With very low interest rates that are close to zero, the bond-stock earnings yield model is not in the danger zone. So the markets attractiveness is from its $\mathrm{PE}$ ratio relative to other assets and markets. There are various ways that one can compute the upper and lower limits but experience has shown that with the various approaches, all of which use out of sample prior data, one usually has the same conclusion. In Figure 2, the limits are simply the trailing mean plus or minus a standard deviation measure so the one sided limit has $95 \%$ of the probability. ${ }^{4}$

\footnotetext{
${ }^{4}$ Using a different index rather than the S\&P500 has the same conclusion but slightly different results.
} 


\section{Relationship between the BSEYD model and the Fed model}

The Bond-Stock Earnings Yield (BSEYD) relates the yield on stocks (measured by the earnings yield) to the yield on nominal Treasury bonds.

$$
B S E Y D(t)=r(t)-\rho(t)=r(t)-\frac{E(t)}{P(t)}
$$

where $\rho(t)$ is the earnings yield at time $t$ and $r(t)$ is the most liquid (10- or 30-year) Treasury bond rate $r(t)$.

Earnings expectations are incorporated in stock prices and discounted via

$$
\tilde{p}(t)=\frac{E(t)}{r(t)}, t=1,2, \ldots
$$

where $E(t)$ denotes the earnings per share at time $t$ and $r(t)$ is the most liquid (10- or 30-year) Treasury bond rate.

Equity earnings per share $\gamma(t)$ is the expected earnings for a unit investment in the stock market with equity shares, $S(t)$, namely

$$
\gamma(t)=\frac{E(t)}{S(t)}
$$

Then,

$$
S(t)=\frac{E(t)}{\gamma(t)}
$$

There is a direct relationship between the equity yield in Equation (3) and the long bond rate in Equation (2). The ratio of the current market value to the theoretical value is the Fed model bond stock yield ratio $\operatorname{BSYR}(\mathrm{t})$

$$
\frac{S(t)}{\tilde{p}(t)}=\frac{E(t) / \gamma(t)}{E(t) / r(t)}=\frac{r(t)}{\gamma(t)}=B S Y R(t) .
$$

Berge, Consigli and Ziemba (2008) used the MSCI index. The danger zone was entered in May 1987 and the correction occurred in October, four months later. During June, July and August investors kept rebalancing their portfolios from the bond to the equity market (MSCI TRI $+13.87 \%$ over the quarter) then the equity market fell $31.80 \%$ in the following quarter (September to November 1987) with the main decline in October. 
The bond stock earnings yield differential that we focus on in this paper is related to the valuation measure and the equity yield via

$$
\begin{gathered}
\frac{S(t)}{\tilde{p}(t)}-1=\frac{B S E Y D(t)}{\gamma(t)} \\
B S E Y D(t)=[B S Y R(t)-1] \gamma(t) .
\end{gathered}
$$

The differential reflects the difference between the current market value and its theoretical value. A more theoretically sound motivation for the predictive ability of the BSEYD is using the basic Gordon formula (see (Gordon 1959)), where E/P is the forward earnings yield (which Schwartz and Ziemba (2000) show is the best predictor of at least individual Japanese stock prices),

$\mathrm{E} / \mathrm{P}$ - nominal yield = equity risk premium - real growth - inflation.

So the BSEYD can be used as a proxy for the unobservable right hand side economic variables. (Lleo and Ziemba 2014a) proposes a slightly different derivation of the relation between the BSEYD and the Gordon growth model.

In its most popular form, the Fed model states that in equilibrium, the one year forward looking earnings yield of the S\&P500 should equal the current yield on a 10-year Treasury Note (Estrada, 2006; Weigand and Irons, 2007; Faugère and Van Erlach, 2009; Maio, 2013; Faugère, 2013), that is

$$
r(t)-\frac{E_{t}^{f}}{P(t)}=0
$$

where $E_{t}^{f}$ is the S\&P 500 one year forward looking earnings. The Fed model is therefore a special case of the BSEYD model when the bond and stock yields are equal, meaning $r(t)=\frac{E_{t}^{f}}{P(t)}$. For given equity yield, the BSEYD can be used to identify zones of under and over valuation and forecast possible forthcoming market adjustments.

Koivu, Pennanen and Ziemba (2005) study the Fed model using a dynamic vector equilibrium correction model with data from 1980 to 2003 in the US, UK and Germany and show that the Fed model had predictive power in forecasting equity prices, earnings and bond yields. The model has been successful in predicting market turns, but in spite of its empirical success and simplicity, the model has been criticized. First it does not consider the role played by time varying risk premiums in the portfolio selection process while it does consider a risk free government interest rate as the discount factor of future earnings. The inflation illusion (the possible impact of inflation expectations on the stock market) as suggested by Modigliani and Cohn (1979) is not taken into consideration. Secondly, the model assumes the comparability of earning price ratios, a real quantity, with a nominal, 
bond induced, interest rate [Campbell and Vuolteenaho (2004), Asness (2000, 2003), and Ritter and Warr (2002) discuss these issues.] Consigli, MacLean, Zhao and Ziemba (2009) propose a stochastic model of equity returns based on an extension of the model inclusive of a risk premium in which market corrections are endogenously generated by the bondstock yield difference. The model accommodates both cases of prolonged yield deviations leading to a long series of small declines in the equity market and the case, peculiar of recent speculative bubbles, of a series of corrections over limited time periods. The inclusion of the yield differential as a key driver of the market correction process is tested and the model is validated with market data

Many of the critics focus on: 1) short term predicability that we know is weak as does Giot and Petitjean (2008), 2) simply do not focus on the long run value of the measure, or 3) dismiss it outright because of the real versus nominal versus real minor flaw as does Montier (2011). Consigli, MacLean, Zhao and Ziemba (2009) use the model to estimate the current fair value of the S\&P500. Of course, market and fair value can diverge for long periods. However, our concern is whether or not the model actually predicts stock market crashes, stock market rallies and good times to be in and out of stock markets. Berge, Consigli and Ziemba (2008) discuss the latter issue and found for five countries (US, Germany, Canada, UK and Japan) that the strategy stay in the market when it is not in the danger zone and move to cash otherwise provides about double the final wealth with less variance and a higher Sharpe ratio than a buy and hold strategy. There is some limited predictability of stock market increases but the evidence supports the good use of the model to predict crashes. In this paper we study the past, including the recent period 2007-2009 for the US, China and Iceland, all of which had large crashes. Shiller (2006) observes, as we have (see Table 34), that low PE periods seem to lead to higher future stock prices and high PE periods to lower future prices. But the presumption is that PE levels may not be enough to call the crashes. The argument in Ziemba (2003) or Ziemba and Schwartz (1991) and here is that it is usually the interplay of interest rates measured by the long bond with the PE ratios that gives the crash signal.

\section{Moving Average and Signal Chart}

In the following sections we use a moving average and a rolling horizon standard deviation to establish the confidence levels. The $h$-day moving average at time $t, \mu_{t}^{h}$, and the corresponding rolling horizon standard deviation $\sigma_{t}^{h}$ given by 
Table 2: Evolution of the P/E Over Selected 20-Year Periods With High Annualized Returns. Source: Bertocchi et al (2010)

\begin{tabular}{lrrrr} 
Beginning Year & Ending Year & Annual Rate of Return & Beginning P/E & Ending P/E \\
\hline 1975 & 1994 & $9.6 \%$ & 10.9 & 20.5 \\
1977 & 1996 & $9.7 \%$ & 11.5 & 25.9 \\
1942 & 1961 & $9.9 \%$ & 12.2 & 20.5 \\
1983 & 2002 & $10.9 \%$ & 7.3 & 25.9 \\
1978 & 1997 & $11.9 \%$ & 10.4 & 31.0 \\
1981 & 2000 & $12.8 \%$ & 8.8 & 41.7 \\
1979 & 1998 & $12.9 \%$ & 9.4 & 36.0 \\
1982 & 2001 & $13.0 \%$ & 8.5 & 32.1 \\
1980 & 1999 & $14.0 \%$ & 8.9 & 42.1 \\
\hline
\end{tabular}

$$
\begin{array}{r}
\mu_{t}^{h}=\frac{1}{h} \sum_{i=0}^{h-1} x_{t-i} \\
\sigma_{t}^{h}=\sqrt{\frac{1}{h-1} \sum_{i=0}^{h-1}\left(x_{t-i}-\mu_{t}^{h}\right)^{2} .}
\end{array}
$$

Rolling horizon means and standard deviations used to compute confidence levels for the BSEYD provide data consistency as they are not overly sensitive to the starting date of the bond yield or stock market data, or to the overall number of data points.

For our analysis of the US market in Section 9, we use a five year horizon, so $h=1260$ as longer time horizons tend to generate a robust signal and eliminate false positives. Five years of historical bond and stock data may be a difficult requirement outside of major markets. For Iceland and China, we use a one year rolling horizon, but tighten the confidence level in order to eliminate false positives. Similarly, in Section 10 we use a one-year horizon to test statistically the predictive ability of the BSEYD on the US market because it is short and can be used on most financial markets without requiring a long data history, making international comparison easier.

The idea behind the BSEYD model is that a crash signal should occur whenever

$$
B S E Y D(t)>C L(t),
$$

where $C L(t)$ represents a one-tail confidence level. The level $C L$ acts as a time-varying threshold for the crash signal. So, a crash signal occurs whenever

$$
S I G N A L(t):=B S E Y D(t)-C L(t)>0 .
$$


Graphically, the threshold for the crash signal is now a horizontal line with value 0, discussed in section 5 and shown below in Figures 30, 31(b), 25, 36(a) and 36(b). These graphs show a calculation of $S I G N A L(t)$ based respectively on a standard one-tail $95 \%$ confidence level and on an application of Cantelli's inequality.

An examination of the BSEYD spread distributions reveals their non-normal nature (see Figures 23, 27 and 37). As a result, standard confidence intervals which are based on a Gaussian assumption may prove inaccurate. In this case, we use Cantelli's inequality, a one-sided version of Chebyshev's inequality, to derive a 'worst case' confidence level (see, for example, Problem 7.11.9 in (Grimmett and Stirzaker 2001)).

Cantelli's inequality relates the probability that the distance between a random variable $X$ and its mean $\mu$ exceeds a number $k>0$ of standard deviations $\sigma$ to this distance as

$$
P[X-\mu \geq k \sigma] \leq \frac{1}{1+k^{2}}
$$

or alternatively

$$
P\left[X-\mu \geq \sigma \sqrt{\frac{1}{\alpha}-1}\right] \leq \alpha,
$$

where $\alpha=\frac{1}{1+k^{2}}$. The parameter $\alpha$ provides an upper bound for a one-tailed confidence level on any distribution, regardless of how different it is from a Normal distribution.

We use Cantelli's inequality with a one-tail confidence level to assess the relative strength of a signal. Using the one-tail confidence level, we obtain the crash signal. We then find the Cantelli probability $\alpha$ giving us a similar signal date to the Gaussian approach. To generate the same signal as a standard $95 \%$ confidence level, we need to select $\alpha=27 \%$ in Cantelli's inequality. Similarly, to generate the same signal as a standard $99 \%$ confidence level, we need to select $\alpha=15.60 \%$

For China, as discussed in section 8 , we used a standard $99 \%$ confidence level to determine the signal. Based on Cantelli's inequality, we expect in the worst case to have a crash signal $15.60 \%$ of the time. Retrospectively, Cantelli's inequality is rather severe since it places the threshold for a signal at a BSEYD spread of $3 \%$ or above, on 372 consecutive trading days from June 9, 2005 to June 30, 2012 (i.e. 20.56\% of the 1809 days for which this measure was computed). By contrast, if we consider the distribution over the entire period, we observe that the spread only exceeded $2.5 \%$ on 3 instances (i.e. $0.17 \%$ of the 1809 days for which this measure was computed). In summary, a standard $99 \%$ confidence level would have been sufficient to determine a clear crash signal.

For Iceland, as discussed in section 7, we use a 95\% confidence level to determine the signal, Cantelli's inequality suggests a worst case probability that $27 \%$ of observations could 
result in a signal. However, lowering the Cantelli probability $\alpha$ from $27 \%$ to $20 \%$ (corresponding roughly to a standard $97.7 \%$ confidence level) does not result in significant loss of responsiveness of the signal, at least for Glitnir and Kaupthing (see Figures 25).

For the United States, as discussed in Sections 9 and 10, our analysis covers a standard one-tail 95\% normal distribution based confidence level and an application of Cantelli's inequality. The conclusions are similar in both cases.

\section{The 2000-2003 crash in the S\&P500}

The S\&P500 was 470.42 at the end of January 1995. It was about 750 in late 1996 at the time of Alan Greenspan's famous speech on irrational exuberance in the US stock market. It peaked at 1527.46 on March 24, 2000, fell to 1356.56 on April 4th, and then came close to this peak reaching 1520 on September 1st, the Friday before Labor Day. The bond-stock crash model was in the danger zone virtually all of 1999 and it got deeper in the danger zone as the year progressed as the S\&P500 rose from 1229.23 at the end of December 1998 to 1460.25 at the end of December 1999. The PE ratio was flat, increasing only from 32.34 to 33.29 while long bond yields rose from 5.47 to 6.69 . The S\&P500 fell to 1085 on Sept 7th prior to September 11, 2001.

Table 3 and Figure 4(a) detail this from January 1995 to December 1999. The spread reached three which was well in the $95 \%$ confidence danger band in April and rose to 3.69 in December 1999. The stage was set for a crash which did occur as shown in Figure 5a. Long term mean reversion suggests that the 1996-2000 S\&P500 values were too high relative to 1991-95 and a linear interpolation of the latter period gives a value close to that in 2002. Meanwhile Hong Kong as shown in Figure 4(b), was also in the danger zone.

The model for Japan was hard to interpret because there were high PE ratios but interest rates were close to zero so one had a close to 0-0 situation so the model did not apply to Japan in 1999. The model was not in the danger zone with return differences close to zero; see Figure 4(c).

We witnessed a dramatic fall in the S\&P500 from its peak of 1527 in March 2000 to its September 17, 2000 low of 1085. Further declines occurred in 2001 and 2002, see Figure 4(c). The lowest close to May 2003 was 768.63 on October 10, 2002. ${ }^{5}$ This decline was similar to previous crashes. There were other signals

History shows that a period of shrinking breadth is usually followed by a sharp decline in stock values of the small group of leaders. Then broader market takes

\footnotetext{
${ }^{5}$ Of course, there was a lower close of 666 in March 2009, just before the big rally into 2014.
} 
Table 3: Bond and stock yield differential model for the S\&P500, 1995-1999. Source: Berge and Ziemba (2001)

\begin{tabular}{|c|c|c|c|c|c|c|c|c|c|c|c|c|c|}
\hline year & month & $\begin{array}{l}\text { S\&P500 } \\
\text { Index }\end{array}$ & PER & $\begin{array}{c}\text { b } \\
\text { 30-yr gov't } \\
\text { bond }\end{array}$ & $\begin{array}{l}\mathrm{c}=1 / \mathrm{a} \\
\text { return on } \\
\text { stocks }\end{array}$ & $\begin{array}{c}\text { b-c } \\
\text { crash } \\
\text { signal }\end{array}$ & year & month & $\begin{array}{l}\text { S\&P500 } \\
\text { Index }\end{array}$ & & $\begin{array}{c}\mathrm{b} \\
\text { 30-yr gov't } \\
\text { bond }\end{array}$ & $\begin{array}{l}\quad \mathrm{c}=1 / \mathrm{a} \\
\text { return on } \\
\text { stocks }\end{array}$ & $\begin{array}{l}\text { b-c } \\
\text { crash } \\
\text { signal }\end{array}$ \\
\hline \multirow[t]{12}{*}{1995} & Jan & 470.42 & 17.10 & 8.02 & 5.85 & 2.17 & 1997 & Jul & 954.29 & 23.67 & 6.78 & 4.22 & 2.56 \\
\hline & Feb & 487.39 & 17.75 & 7.81 & 5.63 & 2.18 & & Aug & 899.47 & 22.53 & 6.71 & 4.44 & 2.27 \\
\hline & Mar & 500.71 & 16.42 & 7.68 & 6.09 & 1.59 & & Sep & 947.28 & 23.29 & 6.70 & 4.29 & 2.41 \\
\hline & Apr & 514.71 & 16.73 & 7.48 & 5.98 & 1.50 & & Oct & 914.62 & 22.67 & 6.46 & 4.41 & 2.05 \\
\hline & May & 533.40 & 16.39 & 7.29 & 6.10 & 1.19 & & Nov & 955.40 & 23.45 & 6.27 & 4.26 & 2.01 \\
\hline & Jun & 544.75 & 16.68 & 6.66 & 6.00 & 0.66 & & Dec & 970.43 & 23.88 & 6.15 & 4.19 & 1.96 \\
\hline & Jul & 562.06 & 17.23 & 6.90 & 5.80 & 1.10 & 1998 & Jan & 980.28 & 24.05 & 6.01 & 4.16 & 1.85 \\
\hline & Aug & 561.88 & 16.20 & 7.00 & 6.17 & 0.83 & & Feb & 1049.34 & 25.09 & 6.00 & 3.99 & 2.01 \\
\hline & Sep & 584.41 & 16.88 & 6.74 & 5.92 & 0.82 & & Mar & 1101.75 & 27.71 & 6.11 & 3.61 & 2.50 \\
\hline & Oct & 581.50 & 16.92 & 6.55 & 5.91 & 0.64 & & Apr & 1111.75 & 27.56 & 6.03 & 3.63 & 2.40 \\
\hline & Nov & 605.37 & 17.29 & 6.36 & 5.78 & 0.58 & & May & 1090.82 & 27.62 & 6.10 & 3.62 & 2.48 \\
\hline & Dec & 615.93 & 17.47 & 6.25 & 5.72 & 0.53 & & Jun & 1133.84 & 28.65 & 5.89 & 3.49 & 2.40 \\
\hline \multirow[t]{12}{*}{1996} & Jan & 636.02 & 18.09 & 6.18 & 5.53 & 0.65 & & Jul & 1120.67 & 28.46 & 5.83 & 3.51 & 2.32 \\
\hline & Feb & 640.43 & 18.86 & 6.46 & 5.30 & 1.16 & & Aug & 97.28 & 27.42 & 5.74 & 3.65 & 2.09 \\
\hline & Mar & 645.50 & 19.09 & 6.82 & 5.24 & 1.58 & & Sep & 1017.01 & 26.10 & 5.47 & 3.83 & 1.64 \\
\hline & Apr & 654.17 & 19.15 & 7.07 & 5.22 & 1.85 & & Oct & 1098.67 & 27.41 & 5.42 & 3.65 & 1.77 \\
\hline & May & 669.12 & 19.62 & 7.21 & 5.10 & 2.11 & & Nov & 1163.63 & 31.15 & 5.54 & 3.21 & 2.33 \\
\hline & Jun & 670.63 & 19.52 & 7.30 & 5.12 & 2.18 & & Dec & 1229.23 & 32.34 & 5.47 & 3.09 & 2.38 \\
\hline & Jul & 639.96 & 18.80 & 7.23 & 5.32 & 1.91 & 1999 & Jan & 1279.64 & 32.64 & 5.49 & 3.06 & 2.43 \\
\hline & Aug & 651.99 & 19.08 & 7.17 & 5.24 & 1.93 & & Feb & 1238.33 & 32.91 & 5.66 & 3.04 & 2.62 \\
\hline & Sep & 687.31 & 19.65 & 7.26 & 5.09 & 2.17 & & Mar & 1286.37 & 34.11 & 5.87 & 2.93 & 2.94 \\
\hline & Oct & 705.27 & 20.08 & 6.95 & 4.98 & 1.97 & & Apr & 1335.18 & 35.82 & 5.82 & 2.79 & 3.03 \\
\hline & Nov & 757.02 & 20.92 & 6.79 & 4.78 & 2.01 & & May & 1301.84 & 34.60 & 6.08 & 2.89 & 3.19 \\
\hline & Dec & 740.74 & 20.86 & 6.73 & 4.79 & 1.94 & & Jun & 1372.71 & 35.77 & 6.36 & 2.80 & 3.56 \\
\hline \multirow[t]{6}{*}{1997} & Jan & 786.16 & 21.46 & 6.95 & 4.66 & 2.29 & & Jul & 1328.72 & 35.58 & 6.34 & 2.81 & 3.53 \\
\hline & Feb & 790.82 & 20.51 & 6.85 & 4.88 & 1.97 & & Aug & 1320.41 & 36.00 & 6.35 & 2.78 & 3.57 \\
\hline & Mar & 757.12 & 20.45 & 7.11 & 4.89 & 2.22 & & Sep & 1282.70 & 30.92 & 6.50 & 3.23 & 3.27 \\
\hline & Apr & 801.34 & 20.69 & 7.23 & 4.83 & 2.40 & & Oct & 1362.92 & 31.61 & 6.66 & 3.16 & 3.50 \\
\hline & May & 848.28 & 21.25 & 7.08 & 4.71 & 2.37 & & Nov & 1388.91 & 32.24 & 6.48 & 3.10 & 3.38 \\
\hline & Jun & 885.14 & 22.09 & 6.93 & 4.53 & 2.40 & & Dec & 1469.25 & 33.29 & 6.69 & 3.00 & 3.69 \\
\hline
\end{tabular}

a more modest tumble. Paul Bagnell in late November 1999 in the Globe and Mail.

Figure 6 shows the rise in Canada on the Toronto stock exchange (TSE300) the during 1999 and 2000 and the subsequent fall in 2001 and 2000. During 1999, the TSE300 gained 31\% but the gain was only $3 \%$ without three very high PE, high cap stocks showing extreme concentration in the market. The largest gainer in market value, Nortel Networks, peaked at US\$120 and was about US\$1.70 at the end of 2002 and lower in 2010 after a reverse stock split. This is shown in Figure 7.

The concentration of stock market gains into very few stocks with momentum and size being the key variables predicting performance was increasing before 1997 in Europe and North America. Table 4 for 1998 shows that the largest cap stocks had the highest return in North American and Europe but small cap stocks outperformed in Asia and Japan. The situation was similar from 1995 to 1999 with 1998 and 1999 the most exaggerated.

The influential book Irrational Exuberance by Yale behavioral finance economist Robert Shiller (2000) hit the market in April 2000. It was a monumental success in market timing, with an especially bearish view that is consistent with our Figure 4(a) and Table 1. Shiller's Figures $8(\mathrm{a})$ and 8 (b) document very high PE ratios in relation to earnings in 2000 with most of the rise in the 1995-2000 period similar to our Table 3 for the S\&P500. His 100- 

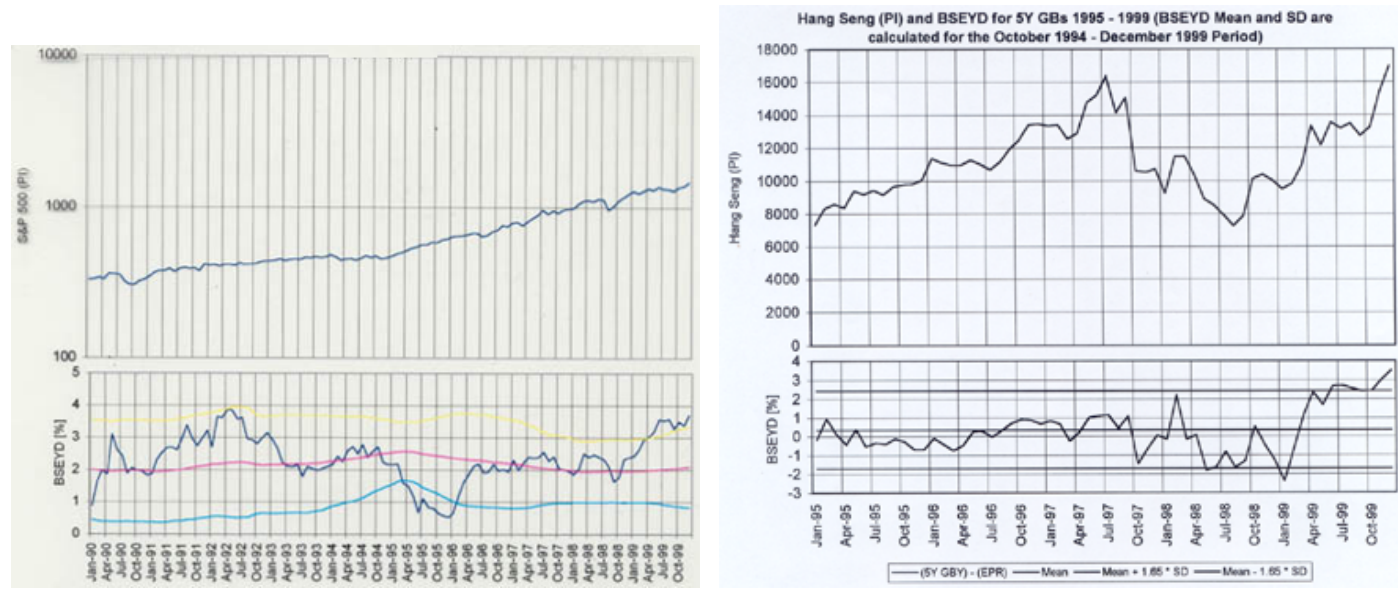

(a) Bond and stock yield differential model for the (b) Hang Seng (PI) and BSEYD for 5Y government S\&P500, 1990-1999. bonds 1995 - 1999 (BSEYD mean and SD are calculated for October 1994 - December 1999)

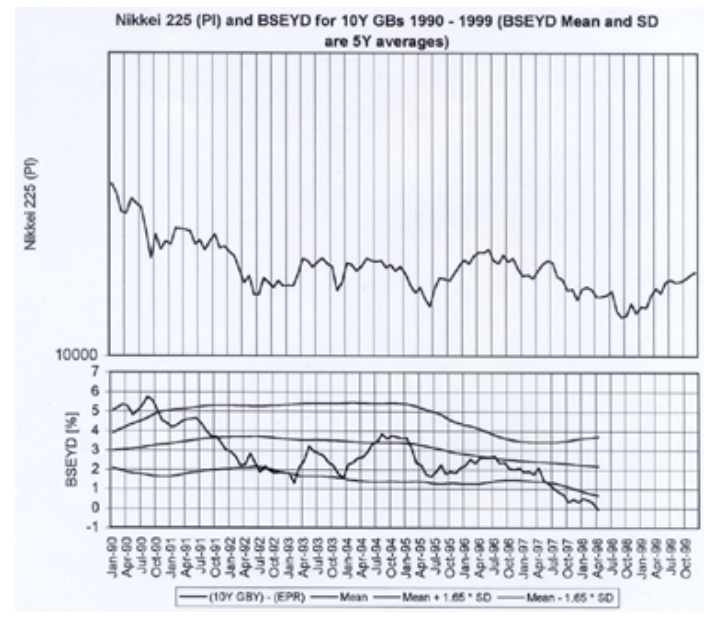

(c) Nikkei stock average and BSEYD for 10Y government bonds (BSEYD mean and SD are calculated for October 1994 - August 1998),

Figure 4: Bond and stock yield differential model for the S\&P500, the Hang Seng and the Nikkei Stock Averages. Source: Berge and Ziemba (2001)]

plus year graphs are very convincing that in 1996-2000 the stock market was over priced relative to historical norms.

Shiller had been predicting a crash since 1996 as reported in Campbell and Shiller (1998). 


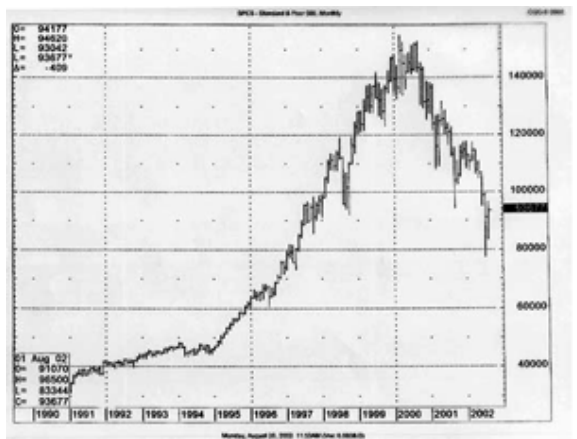

(a) $1991-2002$

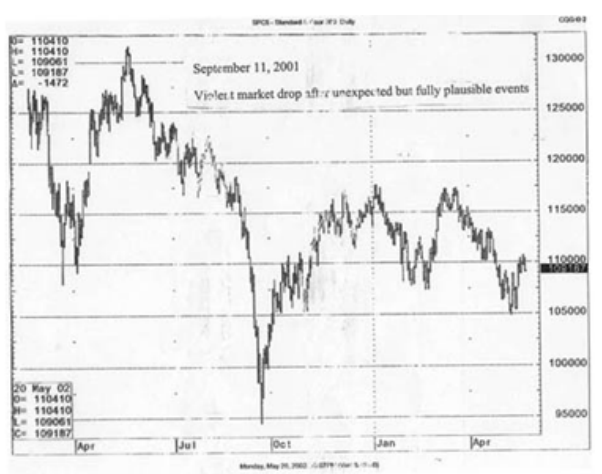

(b) Around Sept 11, 2001

Figure 5: The S\&P500

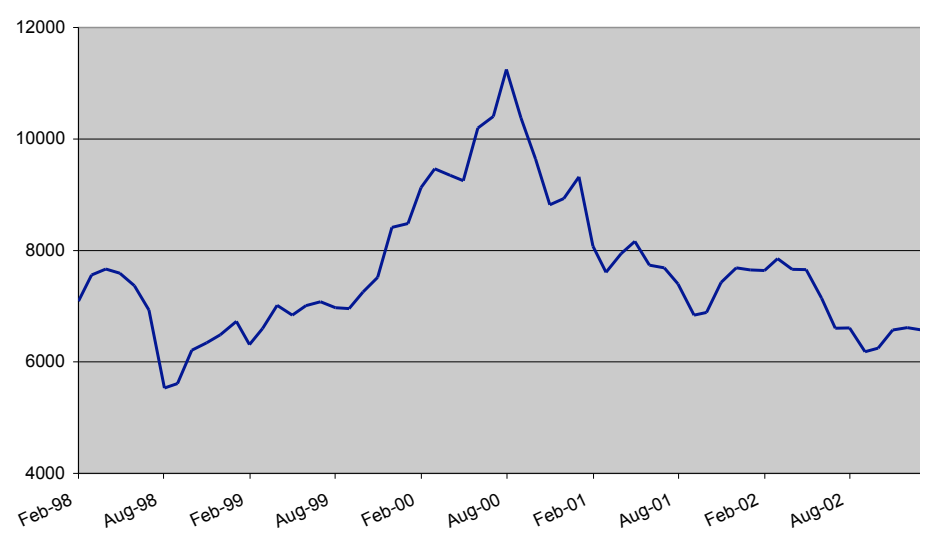

Figure 6: The Toronto Stock Exchange, February 1998 to January 2003

Table 4: MSCI Indices grouped into quintiles by 12/31/97 P/E ratio, 12/31/98

\begin{tabular}{|c|c|c|c|c|c|c|c|c|c|c|c|c|c|c|c|c|c|c|}
\hline \multirow[b]{3}{*}{ Quintile } & \multicolumn{3}{|c|}{ World All } & \multicolumn{3}{|c|}{ North America } & \multicolumn{3}{|c|}{ Europe - All } & \multicolumn{3}{|c|}{ Latin America } & \multicolumn{3}{|c|}{ Asia ex Japan } & \multicolumn{3}{|c|}{ Japan } \\
\hline & & Total & Return & & Total & Return & & Total & Return & & Total P & Return & & Total & Return & & Total & Return \\
\hline & P/E & Equit) & AktCap & $\mathrm{P} / \mathrm{E}$ & Equity & ktCap & P/E & Equity & MktCap & $\mathrm{P} / \mathrm{E}$ & Equity & MktCap & P/E & Equity & Cap & $\mathrm{P} / \mathrm{E}$ & Equity & tCap \\
\hline 1 Highest & 57 & $13 \%$ & $48 \%$ & 48 & $20 \%$ & $63 \%$ & 55 & $25 \%$ & $53 \%$ & 31 & $-38 \%$ & $-31 \%$ & 36 & $-6 \%$ & $7 \%$ & 134 & $8 \%$ & $-5 \%$ \\
\hline 2 & 25 & $13 \%$ & $45 \%$ & 26 & $16 \%$ & $43 \%$ & 24 & $24 \%$ & $25 \%$ & 19 & $-32 \%$ & $-21 \%$ & 18 & $10 \%$ & $10 \%$ & 39 & $16 \%$ & $16 \%$ \\
\hline 3 & 18 & $9 \%$ & $30 \%$ & 20 & $7 \%$ & $24 \%$ & 19 & $16 \%$ & $32 \%$ & 14 & $-38 \%$ & $-28 \%$ & 13 & $15 \%$ & $11 \%$ & 29 & $15 \%$ & $12 \%$ \\
\hline 4 & 14 & $-1 \%$ & $17 \%$ & 17 & $1 \%$ & $30 \%$ & 15 & $-0.4 \%$ & $35 \%$ & 9 & $-34 \%$ & $-37 \%$ & 8 & $-2 \%$ & $13 \%$ & 22 & $28 \%$ & $24 \%$ \\
\hline 5 lowest & 8 & $3 \%$ & $17 \%$ & 13 & $-1 \%$ & $11 \%$ & 10 & $-3 \%$ & $13 \%$ & 5 & $-27 \%$ & $-25 \%$ & 5 & $19 \%$ & $35 \%$ & 14 & $38 \%$ & $32 \%$ \\
\hline
\end{tabular}

His view has not changed and he remains defiantly bearish (as in Campbell and Shiller (2001) which is an update of the 1998 paper) and in later interviews and indeed throughout the 2000s to 2011. His case was helped by three largely unpredictable bad scenarios. Those are the September 11, 2001 attack on the US, the June/July 2002 crises of accounting 


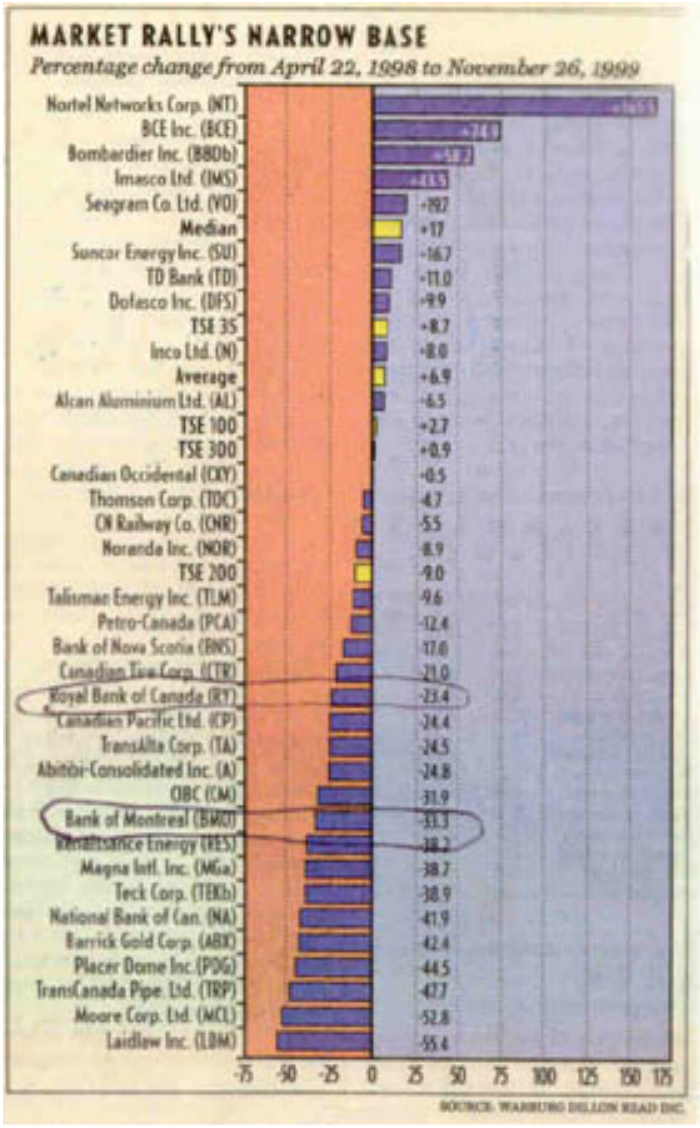

Figure 7: The narrow base of the Toronto Stock Exchange 1999 rally. Source: Globe and Mail 

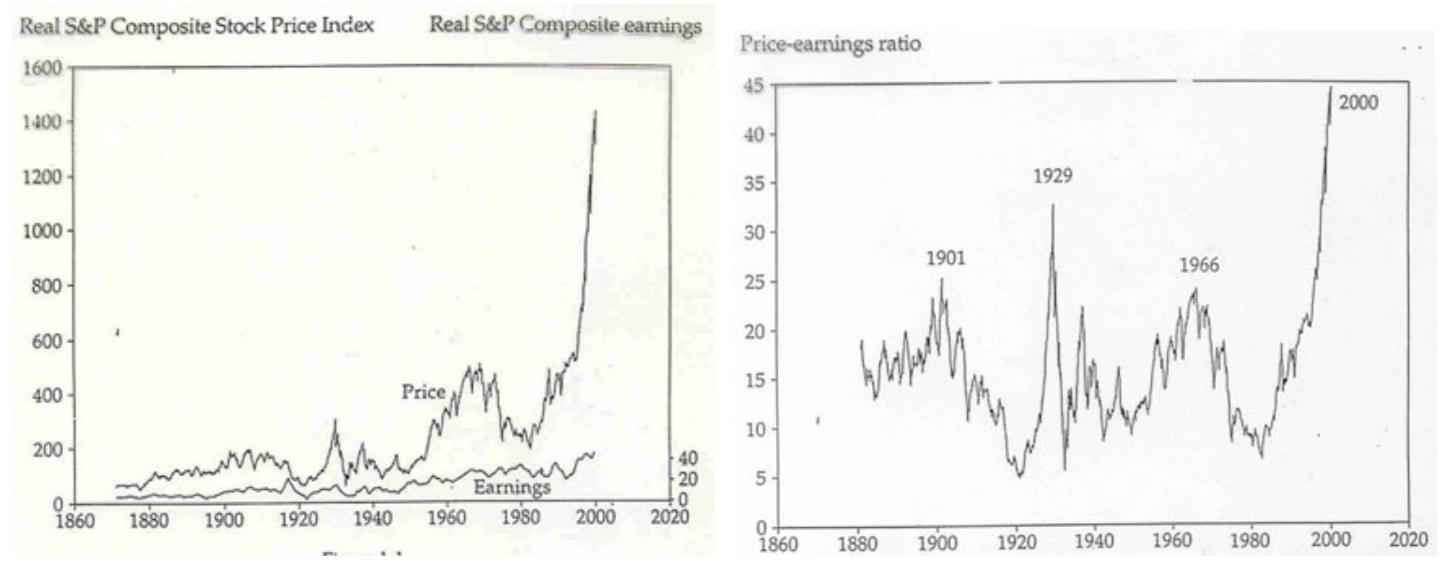

(a) Real S\&P composite price index, monthly (upper (b) Inflation corrected PER, moving average over preseries) and real S\&P composite earnings (lower series). ceding ten years of real S\&P earnings.

Figure 8: Stock prices, earnings and the price earnings ratio, January 1871-January 2000. Source: Shiller (2000)

confidence in the US and the 2003 US/British war with Iraq. One can argue that the second bad scenario is a direct consequence of the 1996-99 bubble period as does the Economist (2002) and in Warren Buffet and Peter Drucker interviews. The latter two sages saw this a long time ago. Also the third bad scenario was a consequence of the first.

Some conclusions are:

1. We should be able to use measures like the bond-stock return difference and research like Shiller's graphs to create better scenarios. According to Chopra and Ziemba (1993), the mean is by far the very most important aspect of return distributions and that is clear here. Figure 9 for the S\&P500 in 2000-2002 reminds us of that.

2. The extent of such danger measures also suggest that the entire distribution from which scenarios are drawn should be shifted left towards lower and more volatile returns. We know that volatility generally, but not always, increases as markets decline. Koivu, Pennanan and Ziemba (2005) show one way to create such better scenarios.

3. The evidence is high that stocks outperform bonds, T-bills and most other financial assets in the long run; see Figures 10(a) and 10(b) and Table 6. Stocks generally outperform in times of inflation and bonds outperform in times of deflation; see e.g. Smith (1924). Why do stocks generally outperform bonds? "A major reason is that 


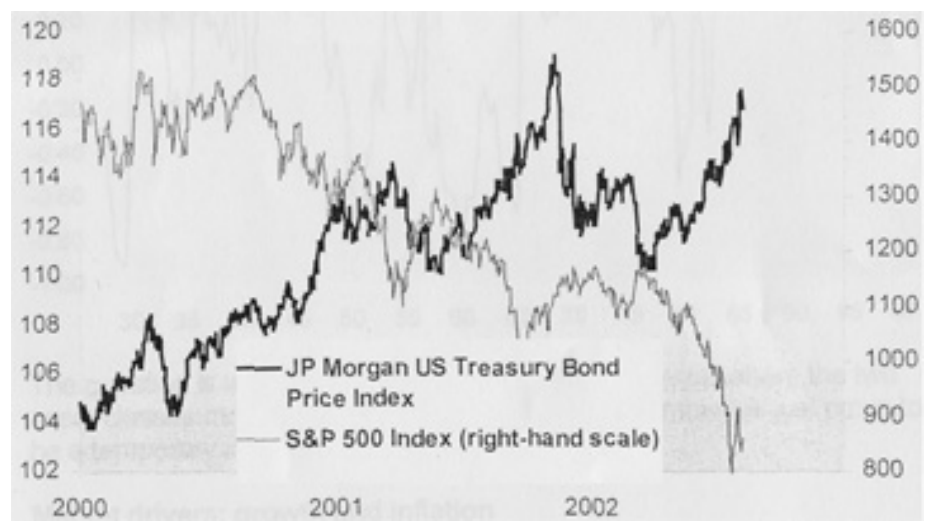

Figure 9: S\&P500 index and US government bonds. Source: Schroder Investment Management Ltd, 2002

businesses retain earnings, with these going onto create more earnings and dividends too." (from the review of Smith (1924) by J. M. Keynes in 1925 quoted in Buffett (2001). In times of growth, firms borrow at fixed cost with the expectation of earning positive economic profit so in the long term, equities as a reflection of this positive income creation should grow at the rate of productivity.

4. There are occasional long periods when stocks underperform alternative asset classes. Figure 11 from Siegel (2008) shows this for the nominal and real 30 stock Dow Jones averages from 1885 to 2006 in 2006 dollars. One sees a quite violent but upward trending path. The DJIA in nominal terms provides a similar but still bumpy path. The effect of dividends tends to smooth this path and provide a substantial part of the total returns.

Figure 9 shows the 2000-2002 period for the S\&P500 and US government bonds. When bonds outperform stocks, as in this latter period, they are usually negatively correlated with stocks as well; see Figure 12 which has rolling correlations. Between 1982 and 1999 the return of equities over bonds was more than $10 \%$ per year in EU countries. The question is whether we are moving back to a period where the two asset classes move against each other or whether this will just prove to be a temporary phenomenon.

Moreover, the historical evidence since 1802 for the US and 1700 for the UK indicates that the longer the period the more likely is this dominance to occur. Indeed, despite long periods with losses in the indices, the total returns can be positive.

Figure 11 shows the real returns without dividends for the 30-stock Dow Jones Average from 1885-2006 in 2006 dollars. 


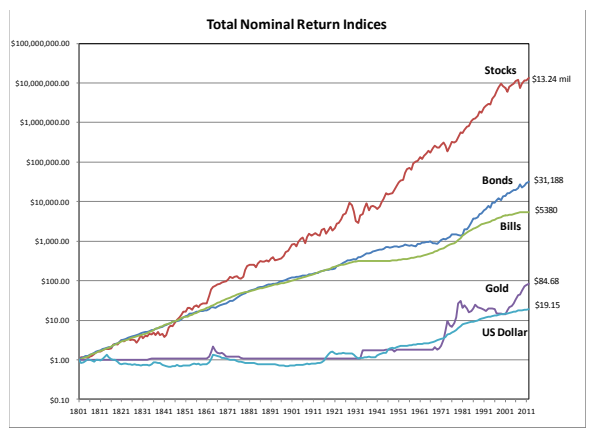

(a) Total nominal return indices, 1802 to 2011

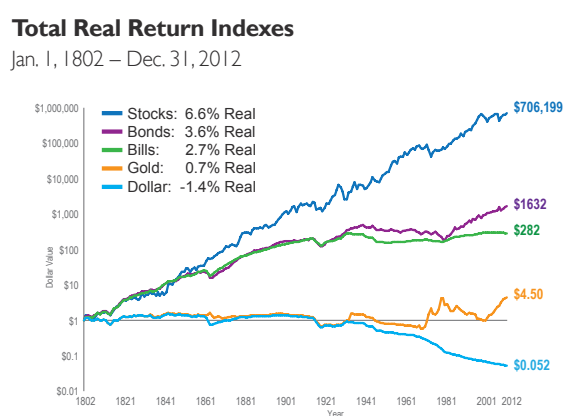

(b) Total real return indices, 1802 to 2012

Figure 10: Returns from US stocks and other assets, 1802-2012. Source: Siegel(2014)

Siegel (2014) has shown that over all thirty year periods from 1900 to 2006 US equities outperformed bonds and in 10- and 20-year periods, stocks have outperformed bonds most, but not all, times. Table 5 shows the impact of dividends.

Table 5: Summary statistics for dividends per share, earnings per share and stock returns for the US economy, 1871 through December 2006. Source: Siegel, 2008

\begin{tabular}{cccccc} 
& $\begin{array}{c}\text { Real GDP } \\
\text { Growth }\end{array}$ & $\begin{array}{c}\text { Real per Share } \\
\text { Earnings Growth }\end{array}$ & $\begin{array}{c}\text { Real per Share } \\
\text { Dividend Growth }\end{array}$ & $\begin{array}{c}\text { Dividend } \\
\text { Yield* }\end{array}$ & $\begin{array}{c}\text { Payout } \\
\text { Ratio* }^{*}\end{array}$ \\
\hline $1871-2006$ & $3.57 \%$ & $1.88 \%$ & $1.32 \%$ & $4.58 \%$ & $58.17 \%$ \\
$1871-1945$ & $3.97 \%$ & $0.66 \%$ & $0.74 \%$ & $5.29 \%$ & $66.78 \%$ \\
$1946-2006$ & $3.09 \%$ & $3.40 \%$ & $2.03 \%$ & $3.53 \%$ & $51.38 \%$ \\
\hline
\end{tabular}

* Denotes median.

There have been four periods in the US markets where equities had essentially zero gains in nominal terms, not counting dividends, 1899 to 1919, 1929 to 1954, 1964 to 1981 and 1997 to 2009. Conversely, there have only been four periods were there were nominal gains not counting dividends: 1919-1929, 1954-1964, 1981-1997 and 2009-2014.

Over 30-year horizons, it is optimal (with a mean-variance model) to be more than $100 \%$ in stocks and short bonds based on the past. Siegel uses various risk tolerance measures such as ultra-conservative and risk taking. These are easy to devise using the Kallberg-Ziemba (1983) results by just assigning Arrow-Pratt risk aversion values as I have done in the second column of Siegel's Table 7. Over $100 \%$ means more than $100 \%$ stocks or a levered long position which would be short bonds or cash. 


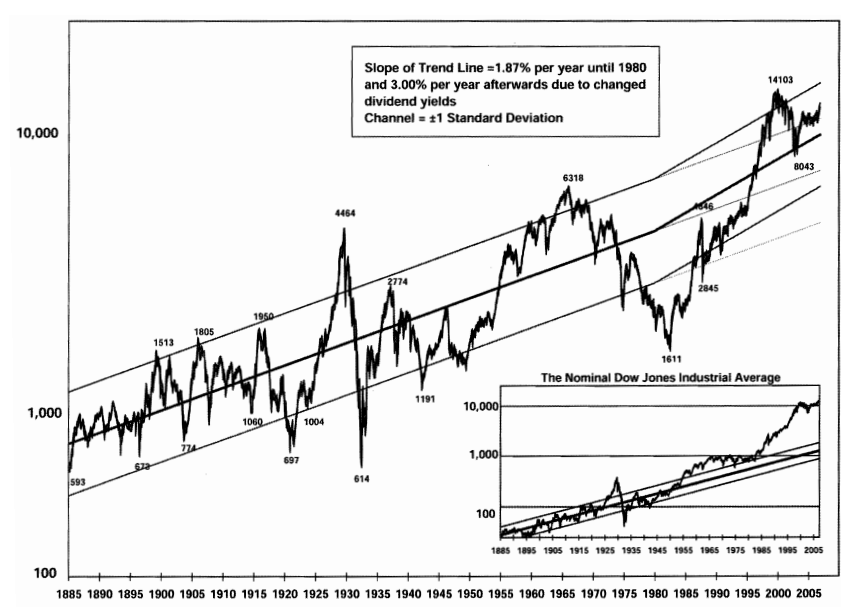

Figure 11: DJIA, February 1885 to December 2006, in 2006 dollars. Source: Siegel, 2008.

5. Stochastic programming models handle extreme event scenarios in a natural way. There is little chance that one can correctly predict events like September 11, 2001's attack. However, scenarios that represent the effect that such events could occur in terms of their impact on market returns can be included. If such events have never occurred before, scenarios can be devised from similar events in other markets and their possible outcomes.

Table 6: Equities have generated superior returns in the long run, December 1925-December 1998. Source: Ibbotson, 1999 in Swensen (2000)

\begin{tabular}{lrc} 
Asset Class & \multicolumn{2}{c}{ Multiple } \\
\hline Inflation & 9 & times \\
Treasury bills & 15 & times \\
Treasury bonds & 44 & times \\
Corporate bonds & 61 & times \\
Large-capitalization stocks & 2,351 & times \\
Small-capitalization stocks & 5,117 & times \\
\hline
\end{tabular}

Figure 13 shows the late 2002 values for the crash indicator using the Fed model. That model uses 10-year bond yields and computes the ratio of the bond and stock yields in terms of a percent over- or under-valued. This measure is a special case of the BSEYD model. This graph from Ned Davis research indicates that very under-valued markets since 1980 have historically had high returns. When the measure is above $15 \%$ then mean S\&P returns average a loss of $6.7 \%$. From 5 to $15 \%$ had mean gains of $4.9 \%$ and below $-5 \%$ had mean gains of $31.7 \%$. In late 2002 /early 2003, the market was at one of its steepest discount to fair value. See Figure 14 for our calculations which mirror those of Davis. The 
Table 7: Portfolio allocation: percentage of portfolio recommended in stocks based on all historical data $\left(R_{A}=\right.$ risk aversion index). Source: Siegel (2008) using theory from Kallberg and Ziemba (1983)

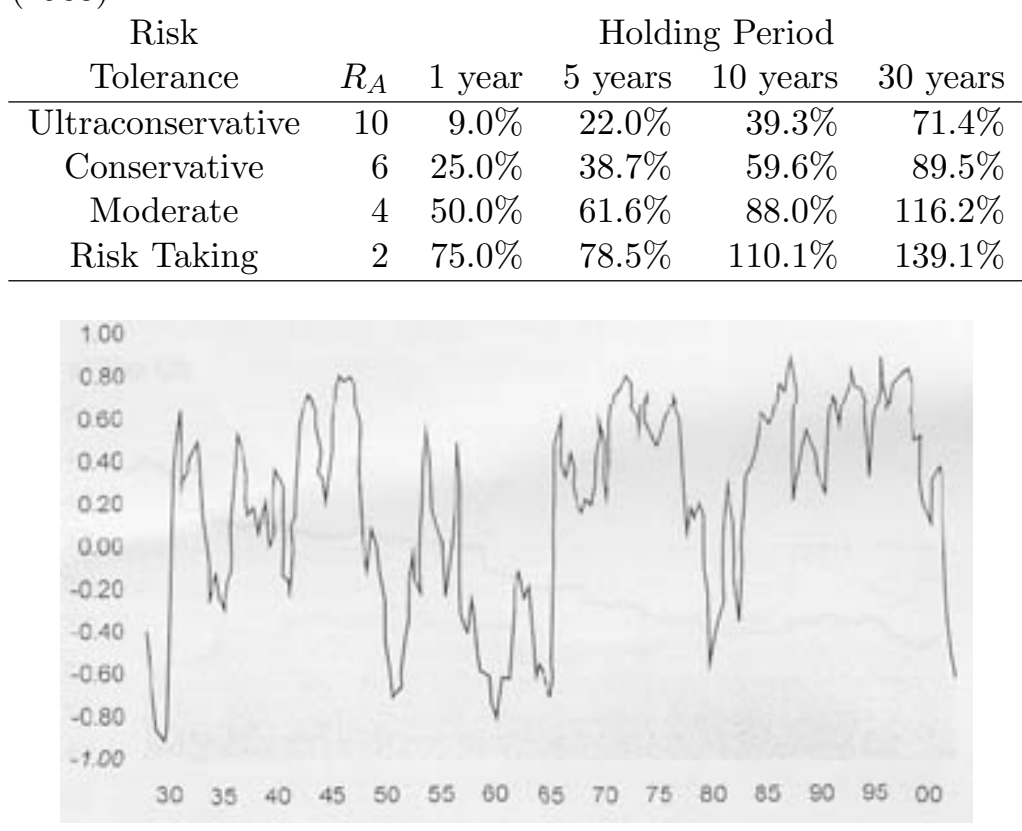

Figure 12: The correlation between US equity and government bond returns. Source: Schroder Investment Management Ltd, 2002

length and depth of the 2000-2003 decline is seen in the jagged parts of Figures 13 and 14 . One sees the initial danger zone for the measure in 1999 but then the market returned to the danger zone in 2001 and 2002 because stock prices fell but earnings fell even more. This was a period where consensus future earnings forecasts were invariably far too optimistic. The S\&P500 index fell from 1460.25 at the end of December 1999 to 885.76 on October 31, 2002 down $37 \%$.

Another valuation measure due to Warren Buffett is the market value of all publicly traded stocks relative to the GNP. Buffett suggests if the measure is 70 or $80 \%$ it's a buy and over $200 \%$ like in 1999 it's a sell. The measure was $133 \%$ in late 2001 and was lower in early 2003 since the stock market has fell more than the GNP. This measure, like Figure 13, signals a recovery in stock prices. ${ }^{6}$ This first appeared in Ziemba (2003), the AIMR

\footnotetext{
${ }^{6}$ The crash and evaluation measures discussed here are based on economic evaluations combined with sentiment. Another interesting approach is through chaos models, a survey of this area and presentation of results is in the 2002 papers of Corcos et al and Sornette and Zhou.
} 


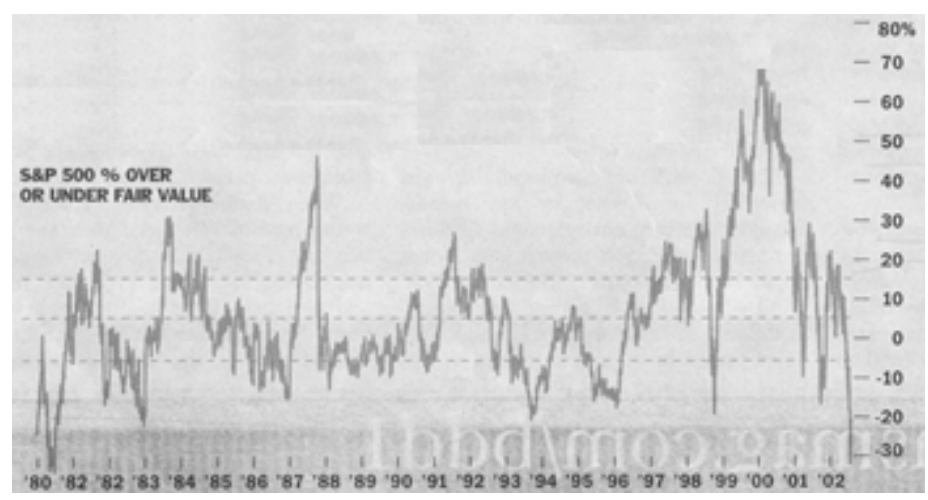

Figure 13: Race to the bottom, Source: Ned Davis Research

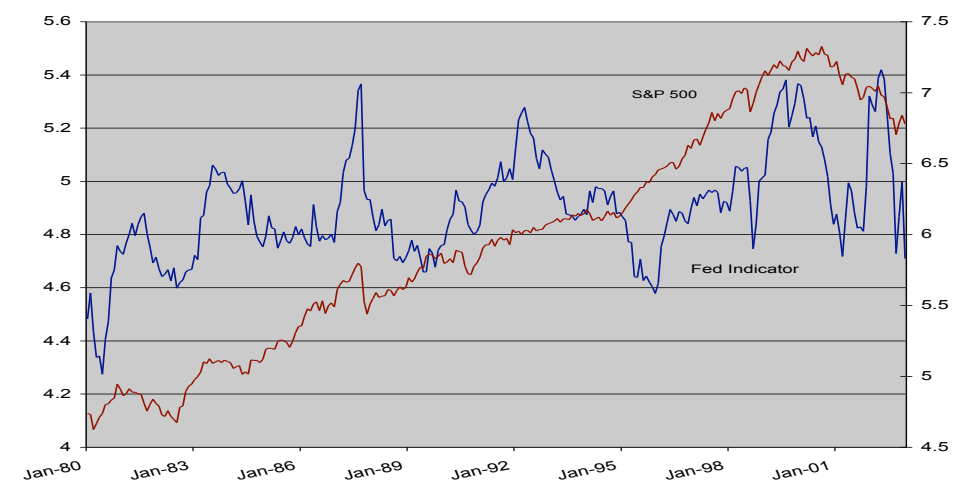

Figure 14: The FED model, 1980-2003. Source: Koivu, Pennanen and Ziemba (2003)

monograph. The Buffett call was right. So was the long bond-stock call.

However, $41 \%$ of the stocks in the S\&P500 did not fall or actually rose during this period and an additional $19 \%$ declined by $10 \%$ or less annualized. These were small cap stocks with market values of $\$ 10$ billion or less; see Figures 15 and 16. The fall in the S\&P500 was mainly in three areas: information technology, telecommunications and large cap stocks. Information technology stocks in the S\&P500 fell $64 \%$ and telecom stocks fell $60 \%$ from January 1 to October 31, 2002. The largest cap stocks (with market caps of $\$ 50$ billion plus) lost 37\%. But most other stocks either lost only a little or actually gained. Materials fell $10 \%$ but consumer discretionary gained $4.5 \%$, consumer staples gained $21 \%$, energy gained $12 \%$, financial services gained $19 \%$, health care gained $29 \%$, industrials gained $7 \%$ and utilities gained $2 \%$. Equally weighted, the S\&P500 index lost only $3 \%$. These values include dividends. The stocks that gained were the very small cap stocks with market caps below $\$ 10$ billion. Some 138 companies with market caps between $\$ 5-10$ billion gained 
$4 \%$ on average and 157 companies with market caps below $\$ 5$ billion gained on average $23 \%$.

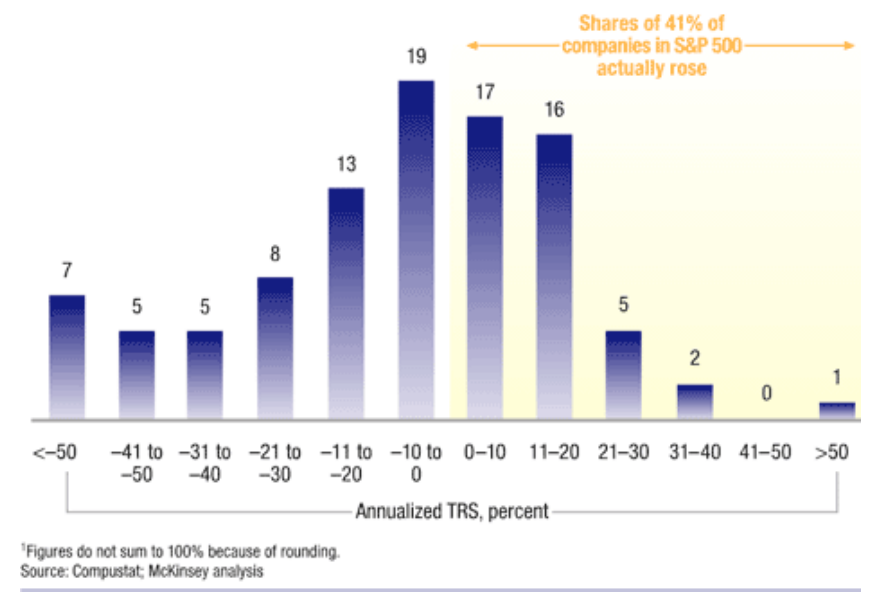

Figure 15: Distribution of annualized total returns of S\&P500 stocks from January 12000 to October 31, 2002 in percentages by categories of returns. Source: Koller and Williams (2003)

\section{Using the BSEYD model for long run investing}

Berge and Ziemba (2003) and Berge, Consigli and Ziemba (2008) study this measure from 1970 and 1975 to 2000 in five major markets, namely the US, Germany, Canada, the UK and Japan.

They compare four strategies for each of the time periods based on the length of the sample from previous data (either 5 or 10 years) to determine the distribution type (historical or assumed normally distributed), the fractile for entry $(70,75,80$ or $85 \%$ ) and the fractile for exit (90 or 95\%), the confidence limits.

The 5 year data intervals were used for the 1980 to 2005 calculations and 10 years for the 1975 to 2005 . The results vary slightly by strategy but the basic conclusions are the same. These results are summarized in Table 8 for strategies 1 and 5 that have 5 and 10 years prior historical data, and $80 \%$ and $85 \%$ entry percentiles and $90 \%$ and $95 \%$ exit percentiles. All the results are in Berge, Consigli and Ziemba (2008) which also lists all the declines of $10 \%+$ during this 20 year period.

The initial wealth start at $\$ 100$ (US), $€ 100$ (Germany), C\$100 (Canada), £100 (UK), and $100 ¥(J a p a n)$ and the terminal values are the gross performance using the strategy signals.. 


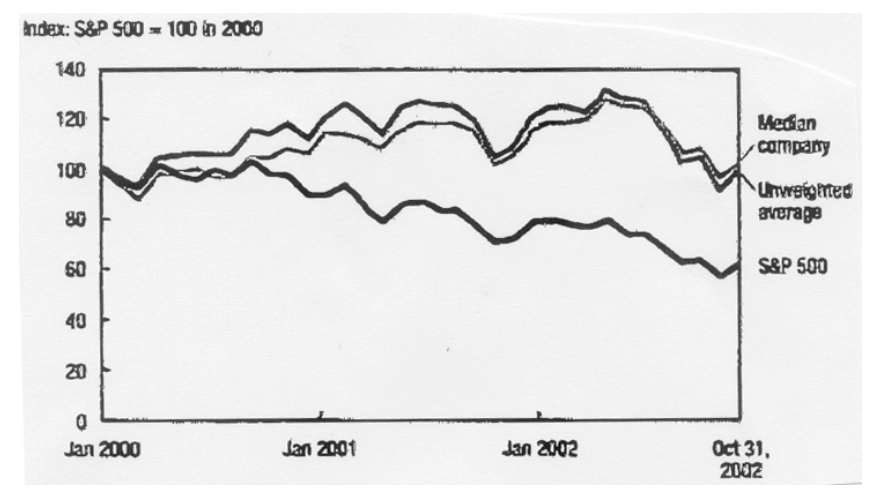

Figure 16: Wealth relatives of S\&P500 stocks, January 2000 to October 2002

The mean excess return is the average monthly excess return of the strategy over the stock market. In each country, the final wealth of the strategies exceeds (except for Canada) buy and hold for the stock market with some months in cash and a higher Sharpe ratio.

\section{The Iceland 2008 crash}

In July 2006 Ziemba was in Iceland speaking at an Operations Research conference and became interested in the economic situation there. Let's first look at the long bond (10year) versus earnings yield differentials for the US, the UK, Japan, France and Germany as of July 12, 2006 as shown in Table 9.

The danger zone requires a long bond rate well past $+2.5 \%$ and close to $+3 \%$ above the stock earnings yield. Table 9 indicates that despite weak global markets in mid 2006, none of these countries were in the danger zone. It would have taken a large increase in long bond rates, which seemed unlikely then, and, of course, did not materialize; and or a large decrease in the earnings yield to reach the danger zone, which would imply a large chance of a fall of $10 \%$ plus within one year.

In Iceland, the 15 stocks in the index have weights of $26.5 \%$ to $1 \%$, see Table 10 . But the main point is that the three largest banks Kaupthing (26.5\%), Lansbanki (13.0\%) and Ghitnir (12.3\%) were more than half the market capitalization and Actavis Banki had $9.9 \%$, and FL Banki another $6.7 \%$. So the banks are well towards two thirds of the index value. And index funds that track the market actually slightly over weight these banks to yield higher returns.

Figure 17, shows the dramatic rise of the stock market particularly since 2004 . It also shows how quickly these drops occur. However, the notable sharp sell-offs, have to a large 
Table 8: Evaluation of the performance of the strategies 1 and 5 versus the market index in the US, Germany, Canada, UK and Japan from 1975 and 1980 to 2005

\begin{tabular}{|c|c|c|c|c|c|c|}
\hline Strategy & $\begin{array}{l}\text { Number of Months } \\
\text { in the Index }\end{array}$ & $\begin{array}{r}\text { Mean Log } \\
\text { Return }\end{array}$ & $\begin{array}{l}\text { Standard } \\
\text { Deviation }\end{array}$ & $\begin{array}{r}\text { Sharpe } \\
\text { Ratio }\end{array}$ & $\begin{array}{r}\text { Mean Excess } \\
\text { Return }\end{array}$ & $\begin{array}{r}\text { Terminal } \\
\text { Value }\end{array}$ \\
\hline US 1 & $319(85,75 \%)$ & 0.01194 & 0.03933 & 0.17814 & 0.00162 & $8,480.41$ \\
\hline US Index (1975 2005) & $372(100 \%)$ & 0.01032 & 0.04347 & 0.12401 & & $4,649.75$ \\
\hline US 5 & $273(87,5 \%)$ & 0.01254 & 0.03887 & 0.19773 & 0.00224 & $5,009.00$ \\
\hline US Index (1980 2005) & $312(100 \%)$ & 0.0103 & 0.04389 & 0.12405 & & $2,490.17$ \\
\hline G 1 & $302(81.18 \%)$ & 0.00881 & 0.0515 & 0.09157 & 0.00068 & $2,652.80$ \\
\hline German Index (1975 2005) & $372(100 \%)$ & 0.00813 & 0.05864 & 0.06886 & & $2,061.27$ \\
\hline G 5 & $279(89.42 \%)$ & 0.00963 & 0.05836 & 0.09405 & 0.00123 & $2,014.62$ \\
\hline German Index (1980 2005) & $312(100 \%)$ & 0.0084 & 0.06201 & 0.0687 & & $1,373.26$ \\
\hline C1 & $295(79.3 \%)$ & 0.00954 & 0.04243 & 0.08053 & -0.0002 & $3,479.37$ \\
\hline Canada Index (1975 2005) & $372(100 \%)$ & 0.00974 & 0.04925 & 0.07337 & & $3,743.49$ \\
\hline C 5 & $273(87.5 \%)$ & 0.00937 & 0.04336 & 0.07839 & 0.00094 & $1,859.80$ \\
\hline Canada Index (1980 2005) & $312(100 \%)$ & 0.00843 & 0.04941 & 0.04977 & & $1,387.23$ \\
\hline UK 1 & $329(88.44 \%)$ & 0.01426 & 0.0502 & 0.14825 & 0.00102 & $20,163.11$ \\
\hline UK Index (1975 2005) & $372(100 \%)$ & 0.01324 & 0.05598 & 0.1147 & & $13,787.40$ \\
\hline UK 5 & $297(95.19 \%)$ & 0.01204 & 0.0442 & 0.12277 & 0.00101 & $4,275.28$ \\
\hline UK Index (1980 2005) & $312(100 \%)$ & 0.01103 & 0.04814 & 0.09179 & & $3,121.47$ \\
\hline $\mathrm{J} 1$ & $222(89.52 \%)$ & 0.00612 & 0.05049 & 0.08427 & 0.00305 & 455.72 \\
\hline Japan Index (5/85 12/05) & $248(100 \%)$ & 0.00307 & 0.05778 & 0.02085 & & 213.88 \\
\hline $\mathrm{J} 5$ & $172(91.49 \%)$ & 0.0012 & 0.0505 & -0.00157 & 0.00168 & 125.35 \\
\hline Japan Index (5/90 $12 / 05)$ & $188(100 \%)$ & -0.00048 & 0.05745 & -0.03062 & & 91.39 \\
\hline
\end{tabular}

extent been blips and there is a question whether these investments can continue to produce similar returns, and if not, whether that will prompt investors to seek other markets.

Index funds such as Gitnir's (\#6) track the market and essentially duplicate it as shown in Figure 17. These values are net of real inflation (2-4\%) and show a high rate of return since 1995. There were losses during 2000 and 2001 but very large gains in 2002-2005.

The stock market increased in 2006 then declined during the $20 \%$ currency depreciation that started in February. The real issue is whether these high prices are sustainable, and how much they depend on continuing high returns from the foreign assets of the banks and companies. The PE ratio of the index in April 2006 was 16.3 (with a $44 \%$ real increase in stock prices since April 2005 when the PE ratio was 17.3). At the same time, the current account deficit increased from $9.3 \%$ of GDP to $16.5 \%$. According to the CBI, there is a future PE ratio of 11.1 when financial companies are included and 14.2 without.

In the book Ziemba and Ziemba (2007) with data up to July 2006 and a postscript to March 2007, the Iceland stock-bond crash measure was as in Table 11:

Figure 18 shows the long term nominal bond yields and Figure 19 shows the term structure of interest rates as of June 16, 2006, a short rate of $13 \%$ and a long rate (5 year) of $9.4 \%$. Using the future PE ratio of all 15 stocks (financial and non-financial) gives the bond-stock 
measure at $+0.39 \%$ and out of the danger zone; see Table 11 .

Table 11 provides two bond stock measure calculations. The index measure is out of the danger zone. However the non-financial sector was in the danger zones but its weight was not enough to pull down the whole market according to the script of the bond-stock crash measure.

The low PE plus the lower long term interest rates still at about $9 \%$ but substantially below the $14.25 \%$ projected to $16 \%$ short rates made the market look risky. So did the parabolic increase of the index in real terms from 1997-2006 shown in Figure 17 . But there was no signal yet for a crash. Lleo and Ziemba (2012) have studied this crash as well as the one in 2007 in China, and 2007-09 in the US which is discussed in the following two sections of this paper.

Doing the calculation with the past earnings PE multiple on the non financials and a blended short/long interest rate of $11 \%$ puts the non-financial stock index measure at $4.87 \%$ (which is in the danger zone). So the conclusion was cloudy. Ziemba and Ziemba (2007) wrote: a crash may be avoided but the market looks very risky.

\section{Who owns these equities?}

Table 12 indicates that the banks own $41.5 \%$, and the pension funds $29.1 \%$ so they who have been the major benefactors of the 2002-2006 (Feb rise) and would be the major losers (unless they sell or hedge) in a crash so Ziemba and Ziemba said in 2007. And indeed they were.

\subsection{Prospects for the Future as discussed in Ziemba and Ziemba (2007)}

The second half of 2006 and 2007 will be a crucial period in Iceland. The rising inflation and overheated economy are likely to lead naturally to higher interest rates. These in turn will lead to other stresses on the economy. It will be essential that the investments of Icelandic companies and banks continue to perform well; should some of these deals fail, the impact on investor confidence could be damaging to the currency, stock and bond markets. However the strength of the financial system, the hedging and operating environment, has significant strengths. The evidence points to a weak housing market, high interest rates, a risky stock market and an economy that, despite the troubles, will possibly limp through for better times in 2008 . 


\subsection{Postscript, March 2007 from Ziemba and Ziemba (2007)}

Several developments have transpired in the second half of 2006. First, the pace of inflation growth is dropping. According to the Kaupthing Bank, Inflation has fallen from a yearly rate of $7.3 \%$ in November 2006, to 7.0 in December and a projected 6.7\% in January . Second, economic growth is slowing to $0.8 \%$ in Q3 2006 for an yearly rate of about $3 \%$ in 2006. The rate of increase of the property index is dropping dramatically. There are no losses yet though they loom on the horizon. The property index was up $4.8 \%$ in 2006 . Third, the trade deficit remains high and is increasing because imports are growing while exports are flat. Fourth, consumer confidence remains very high. Fifth, short term interest rates, which were $13 \%$ in July 2006 are $14.25 \%$ following an unexpected 25 basic point rise on December 21, 2006. Long rates remain in the $9 \%$ area. Some, like the Kaupthing Bank, think this is the last interest rate hike but that rates will remain high. Others, like Danske bank, think the short rates might go to $16 \%$ and that a severe growth slump and likely a recession are very likely.

So the country is risky for investment. Sensing this riskiness the S\&P rating agency lowered the foreign currency sovereign credit ratings of long term debt from AA- to $\mathrm{A}+$ and for short term debt from A-1+ to A-1. Finally the stock market continues to rise and is just now slightly above the February 2006 peak when it fell about $20 \%$ during the financial crisis at that time as described above.

The 15 stock index was up $15.8 \%$ in 2006 and dividends $19.0 \%$ with a $3.8 \%$ increase in December 2006. In January 2007 the index has risen an additional 8.3\% to the 22nd, Glitnir forecasts a $21 \%$ rise in 2007 . With the long term (5 year bond) interest rate still at $9 \%$ and the price earnings ratio such that the earnings to price yield is in the $10 \%$ area, the bond stock measure is still not in the danger zone.

But the least slip in earnings would put it in the danger zone. The slowing of housing price increases which look like they will turn to decreases soon and the possible recession and at least a major slowdown suggest that these earnings will drop. That coupled with the very high short term interest rates which are likely to stay high or even climb suggest that the stock market is very risky.

In the discussion in Ziemba and Ziemba (2007) with data to July 2006 but a postscript to March 2007 was guarded pessimism - we thought that it would crash but the bond-stock yield measure was not quite there yet.

Figure 20 shows that in the fall of 2007, the long bond interest rates did get above $10 \%$ and that with an increase in the PE ratio respectively to 10.91 for Glitnir as of October 10, 11.09 for Kaupthing as of October 11 and 9.94 for Lansbanki as of October 17 show that the signal did predict the massive crash. The market peaked at 8174.28 on July 18, 2007 starting in 2002 at 1180.75 . Then it fell to 5803.55 by the end of December 2007. The 
complete collapse came in 2008 with the market falling about $90 \%$ to end 2008 at 581.76 . The bottom of the market was at 491.58 on February 2, 2010 and as of November 30, 2010 has risen to 579.15 and currently was 864.93 on December 31, 2013. Table 13 summarizes the year to year story and Figure 21 shows the index values from 1993 to 2014

Figure 22 shows the price-earnings ratios for the three top banks.

Iceland is a small country with only 300,000 people. From the 2002 to 2007, the economy and asset prices rose dramatically with much leveraging of investments, especially by the banks. This led to high interest rates of about $10 \%$ long term and $16 \%$ short term. Eventually, it all collapsed in the wake of the 2007-2009 worldwide financial crisis. And the decline was a massive crash of $-95 \%$ in the equity index and a currency collapse.

Figure 17, shows the dramatic rise of the stock market particularly since 2004. It also shows how quickly these drops occur. However, the notable sharp sell-offs, have to a large extent been blips and there was a question whether these investments could continue to produce similar returns, and if not, whether that would prompt investors to seek other markets.

Figure 23 shows the BSEYD spreads for the three top banks and Figure 25 shows the bond-stock earnings yield crash measure by month. Like China, the BSEYD distributions of these three largest banks are not normally distributed and have very fat left tails.

Finally, the question of whether or not the bond-stock earnings yield model predicted the crash is studied in Figures 25ace which use 95\% one sided confidence intervals using moving averages. These graphs show that the crash was predicted. For Kaupthing, the danger zone was penetrated on September 28, 2007, two months after the July 18 peak and less than a month before the November 11 crash. Finally, for Glitnir, the signal was much earlier on October 10, 2006, some thirteen months before the crash. Finally, for Lansbanki, the danger signal was on February 13, 2007. Figure 23bdf show the BSEYD using Cantelli's inequality to account for the non-normality of the BSEYD measure. We focus on the largest banks because they led the market into the collapse. The smallest stocks were in the danger zone in 2006 as discussed in Ziemba and Ziemba (2007) but not the large banks then. 
Table 9: Long-bond (10 yr) versus earning yield differentials for major countries, July 12, 2006. Source: Ziemba and Ziemba (2007)

$\begin{array}{lrrrrr} & \text { S\&P500 } & \text { FTSE200 } & \text { Nikkei225 } & \text { CAC40 } & \text { DAX30 } \\ \text { Index } & 1259 & 5861 & 15249 & 4942 & 5638 \\ \text { A) PE ratio } & 16.86 & 16.61 & 36.26 & 13.82 & 13.33 \\ \text { B) Stock Return (1/A) } & 5.93 \% & 6.02 \% & 2.76 \% & 7.24 \% & 7.50 \% \\ \text { C) Bond Return (10 yr) } & 5.10 \% & 4.67 \% & 1.94 \% & 4.10 \% & 4.09 \% \\ \text { D) Crash Signal (C-B) } & -0.83 & -1.35 & -0.82 & -3.14 & -3.41\end{array}$

Table 10: Stock market index. Source: Glitnir (2006b)

\begin{tabular}{|c|c|c|c|c|c|c|}
\hline \multicolumn{4}{|c|}{ Weights } & \multicolumn{3}{|c|}{ Real rates of return } \\
\hline \multicolumn{2}{|c|}{ Company } & Fund & Index & & Fund & Index \\
\hline 1 & Kaupthing Banki hf. & $27.2 \%$ & $26.5 \%$ & 2005 & $56.5 \%$ & $54.5 \%$ \\
\hline 2 & Landsbanki Islands hf. & $13.1 \%$ & $13.0 \%$ & 2004 & $49.1 \%$ & $47.2 \%$ \\
\hline 3 & Glitnir Banki hf. & $12.5 \%$ & $12.3 \%$ & 2003 & $42.7 \%$ & $40.7 \%$ \\
\hline 4 & Straumur Buróarás Fjárfes & $8.9 \%$ & $8.9 \%$ & 2002 & $20.7 \%$ & $19.2 \%$ \\
\hline 5 & Actavis Banki hf. & $10.1 \%$ & $9.9 \%$ & 2001 & $-16.4 \%$ & $-16.6 \%$ \\
\hline 6 & FL Banki hf. & $6.3 \%$ & $6.2 \%$ & 2000 & $-16.7 \%$ & $-17.2 \%$ \\
\hline 7 & Bakkavör Group hf. & $4.0 \%$ & $4.1 \%$ & 1999 & $36.7 \%$ & $36.4 \%$ \\
\hline 8 & Avion Group hf. & $3.7 \%$ & $3.7 \%$ & 1998 & $6.3 \%$ & $3.4 \%$ \\
\hline 9 & Mosaic Fashions hf. & $2.7 \%$ & $2.6 \%$ & 1997 & $9.0 \%$ & $10.2 \%$ \\
\hline 10 & Ossur hf. & $2.2 \%$ & $2.2 \%$ & 1996 & $44.1 \%$ & $57.3 \%$ \\
\hline 11 & 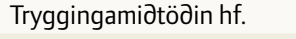 & $2.1 \%$ & $2.0 \%$ & 1995 & $33.4 \%$ & $31.1 \%$ \\
\hline 12 & Dagsbrún hf. & $1.5 \%$ & $1.5 \%$ & & & \\
\hline 13 & Alfresca hf. & $1.2 \%$ & $1.2 \%$ & & & \\
\hline 14 & Fjárfestingafélagið Atorka & $1.0 \%$ & $1.0 \%$ & & & \\
\hline 15 & Grandi hf. & $1.0 \%$ & $1.0 \%$ & & & \\
\hline
\end{tabular}

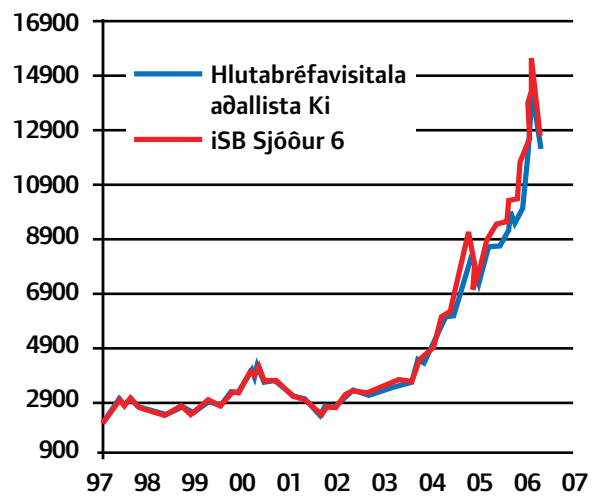

Figure 17: The Iceland equity index and its growth in real terms from 1997-2006. Source: Glitnir (2006b). 


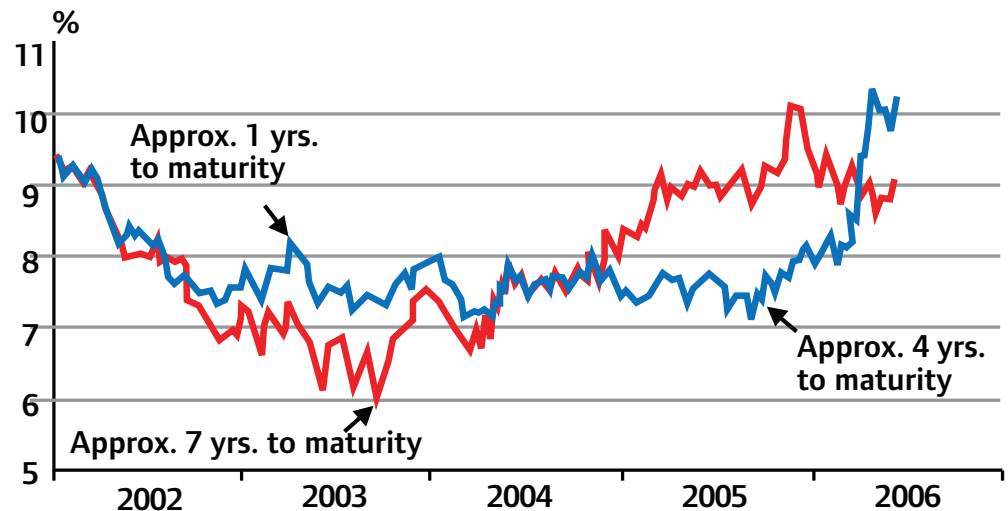

Figure 18: Long term nominal Treasury bond yields, June 16, 2006
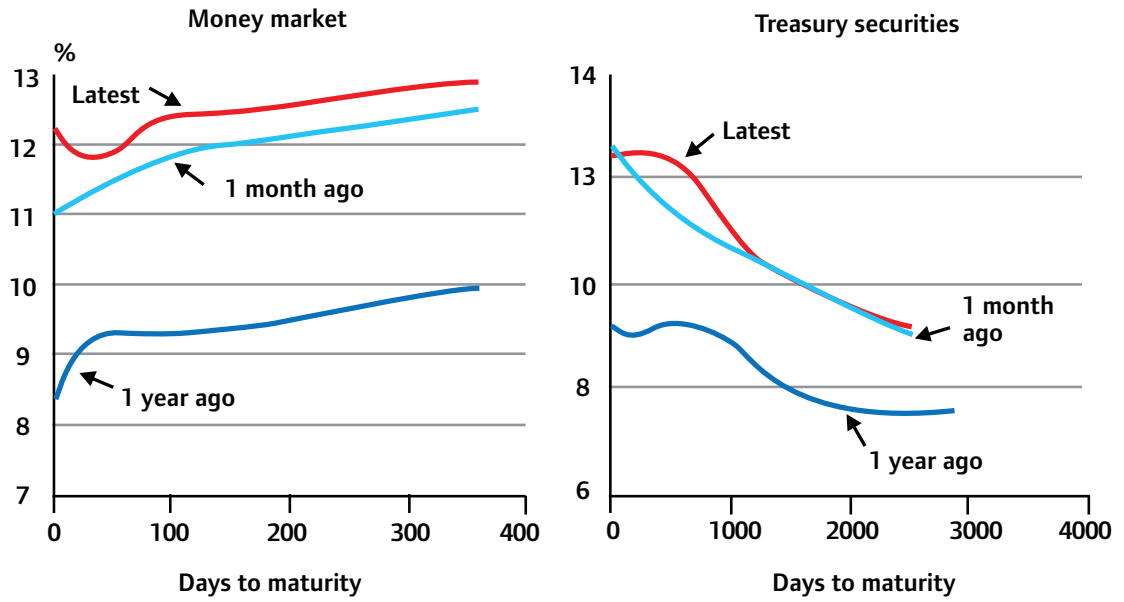

Figure 19: Term structure of nominal interest rates, June 16, 2006.

Table 11: Bond-stock measure calculations in Iceland index 16 nonfin 15 in index
A) PE ratio
11.1
B) Stock Return $(1 / \mathrm{A})$
$6.13 \%$
$9.01 \%$
C) Bond Return (5 yr)
$11.00 \%$
$9.4 \%$
D) Crash Signal (C-B)
$4.87 \%$
$0.39 \%$ 
Table 12: Main owners of securities in February 2006. Source: CBI (2006, p 32). Numbers are in indicated in millions of Icelandic króna (M.kr)

\begin{tabular}{lrrrr} 
M.kr & Equities & \% & HFF bonds & \% \\
Households & 285,690 & $11.7 \%$ & 3,042 & $0.8 \%$ \\
Housing Financing Fund & & $0.0 \%$ & 18,275 & $4.9 \%$ \\
Commercial banks and saving banks & 242,051 & $9.9 \%$ & 153,492 & $41.5 . \%$ \\
Investment banks & 70,921 & $2.9 \%$ & 10,927 & $3.0 . \%$ \\
Securities companies & 18,646 & $0.8 \%$ & 1,093 & $0.3 \%$ \\
Investment funds & 39,362 & $1.6 \%$ & 32,663 & $8.8 \%$ \\
\hline Pension funds & 217,292 & $8.9 \%$ & 107,541 & $29.1 \%$ \\
Insurance companies & 58,094 & $2.4 \%$ & 5,951 & $1.6 . \%$ \\
Businesses & 864,701 & $35.4 \%$ & 2,890 & $0.8 \%$ \\
Non-residents & 523,776 & $21.4 \%$ & & \\
Others & 7,663 & $0.3 \%$ & 1,545 & $0.4 \%$ \\
Custody accounts & 113,701 & $4.7 \%$ & 32,327 & $8.7 \%$ \\
Total & $2,441,897$ & $100.0 \%$ & 369,746 & $100.0 . \%$
\end{tabular}

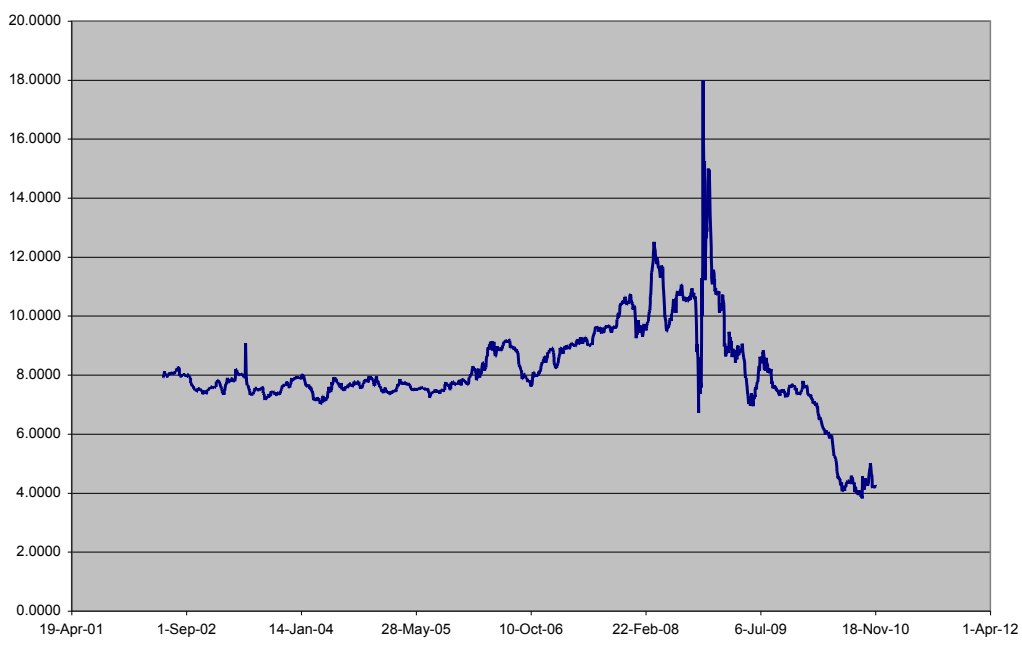

Figure 20: Iceland Treasury note (long bond) maturing May 17, 2013 


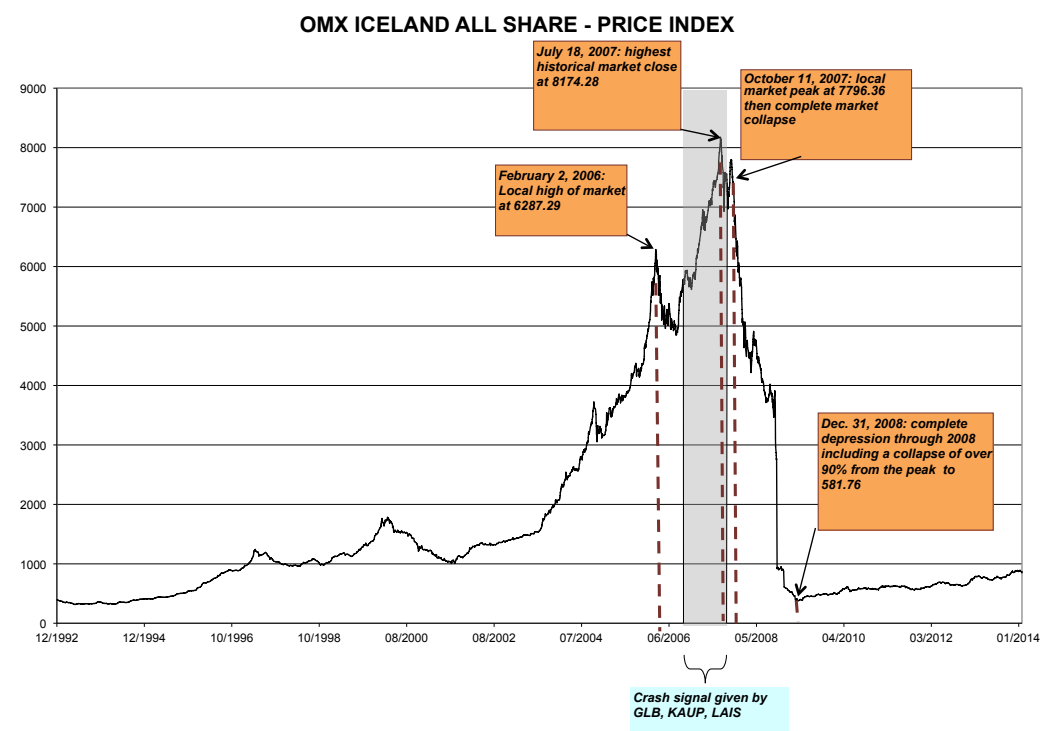

Figure 21: Iceland stock index price level

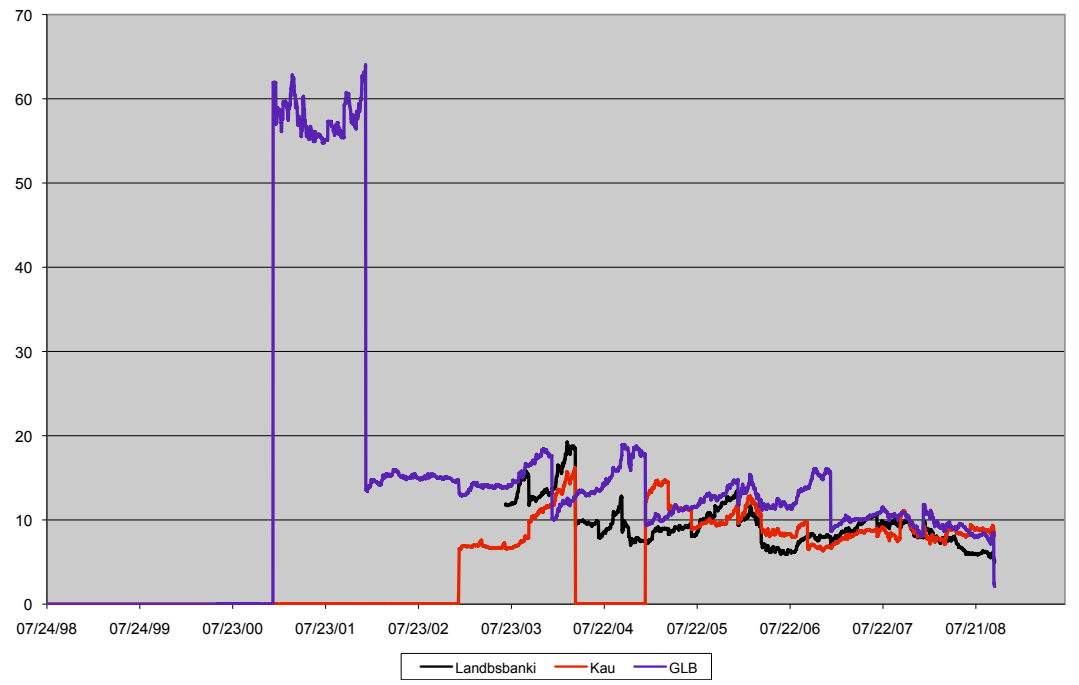

Figure 22: Price-earnings ratios for the three top Icelandic banks 
Table 13: Highlights for the Iceland stock index ICEXI-OMZ 1998-2014 with start value $=1000$ on December 31, 1997

Date

Feb 11, 1998

Dec 31, 1998

Dec 31, 1999

Dec 31, 2000

Dec 31, 2001

Dec 31, 2002

Dec 31, 2003

Dec 31, 2004

Dec 31, 2005

Feb 2,2006

Aug 2, 2006

Dec 31, 2006

July 18, 2007

Aug 16, 2007

Oct 11, 2007

Dec 31, 2007

Dec 31, 2008

Dec 31, 2009

Feb 2, 2010

Nov 30, 2010

Dec 31, 2010

Jan 31, 2011

Jun 30, 2011

December 31, 2011

June 30, 2012

December 31, 2012

December 31, 2013

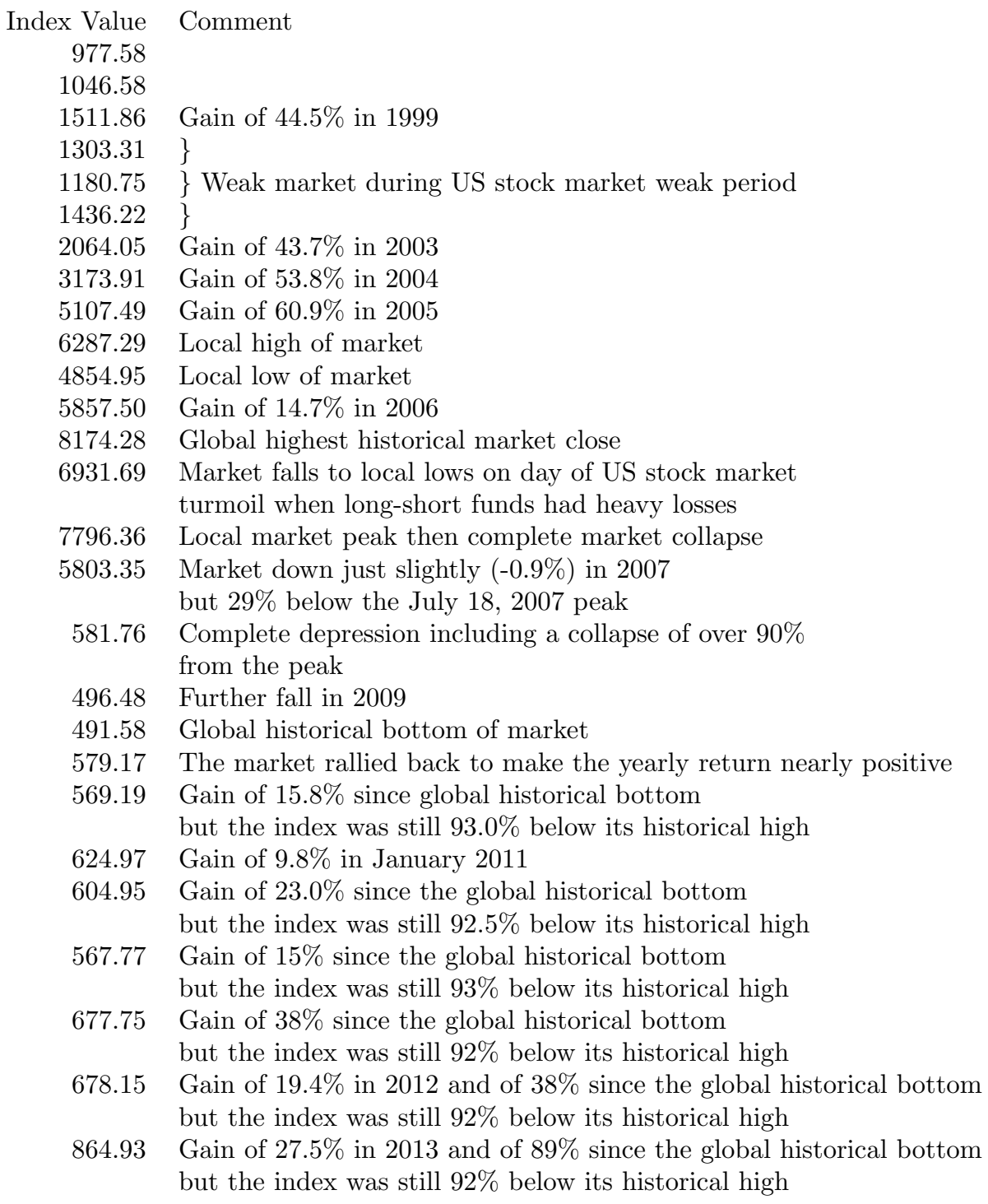
but the index was still $92 \%$ below its historical high

864.93 Gain of $27.5 \%$ in 2013 and of $89 \%$ since the global historical bottom but the index was still $92 \%$ below its historical high 


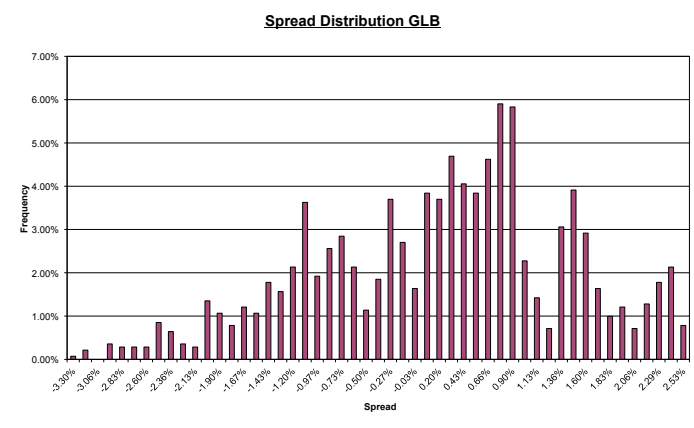

(a) Glitnir, MA

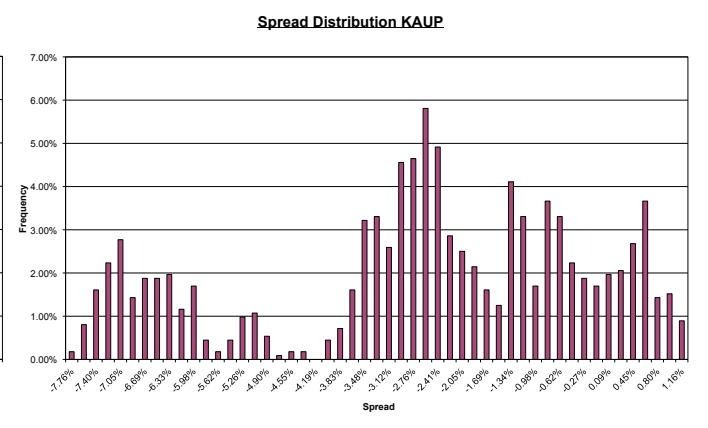

(b) Kaupthing, MA

Spread Distribution LAIS

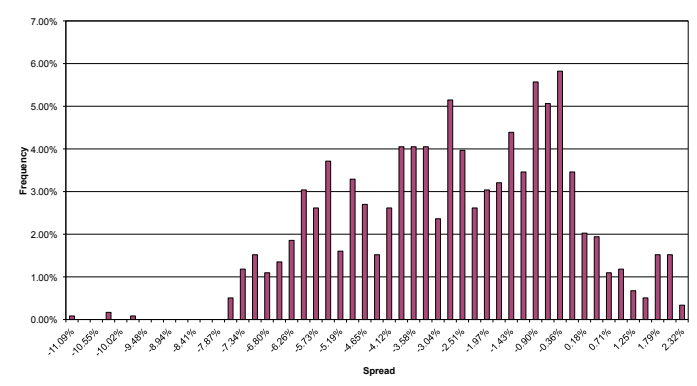

(c) Lansbanki, MA

Figure 23: BSYEM Spread Distributions, Iceland 


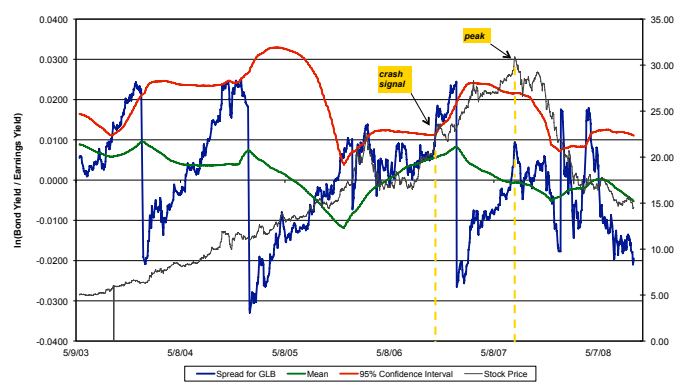

(a) Glitnir, MA

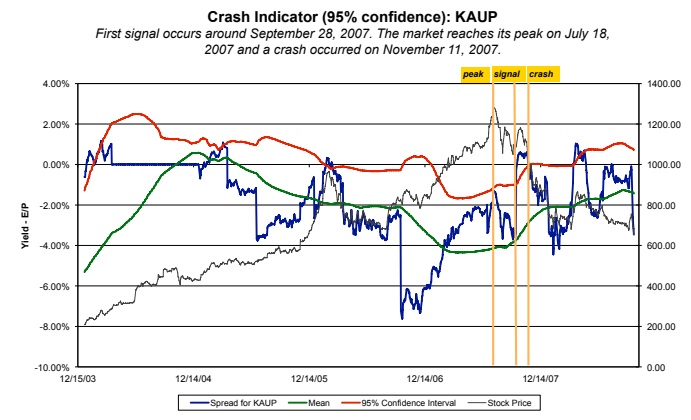

(c) Kaupthing, MA

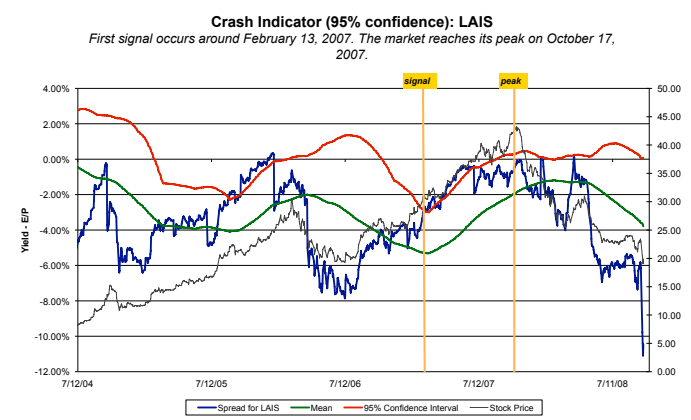

(e) Lansbanki, MA

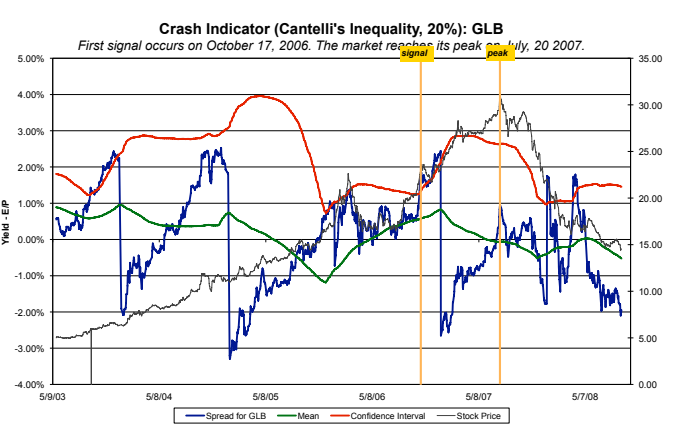

(b) Glitnir, MACI

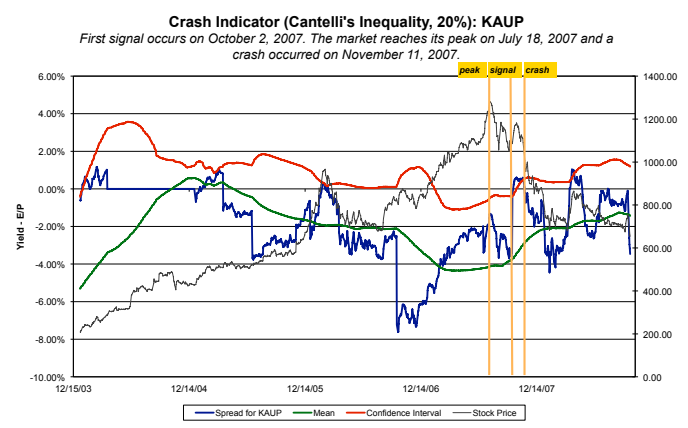

(d) Kaupthing, MACI

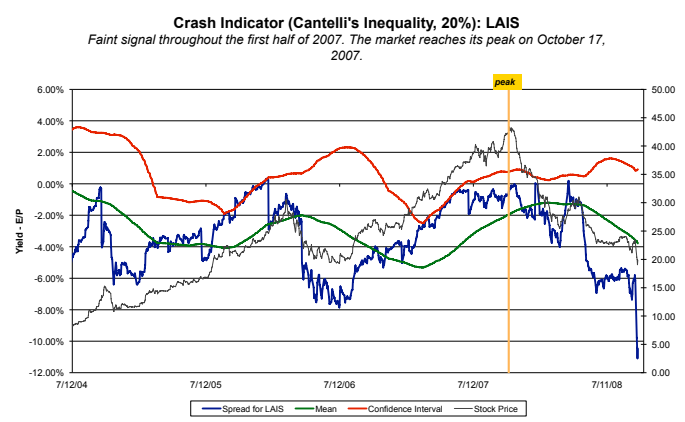

(f) Lansbanki, MACI

Figure 24: Crash Indicators, Iceland 


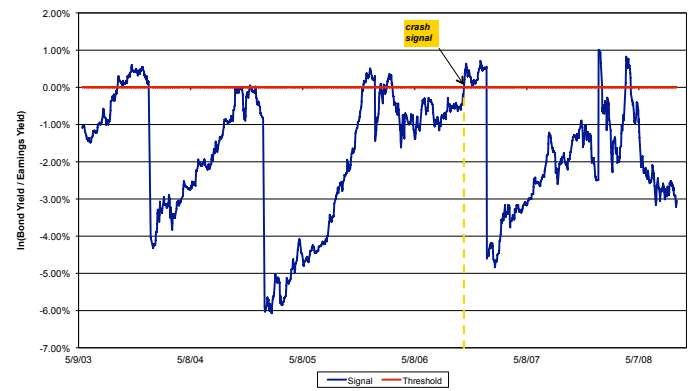

(a) Glitnir, MA

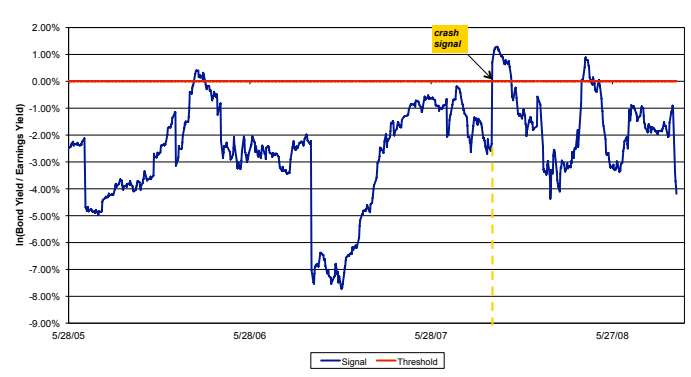

(c) Kaupthing, MA

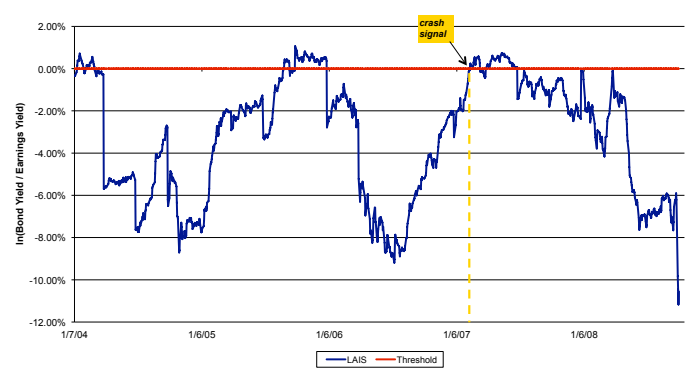

(e) Lansbanki, MA

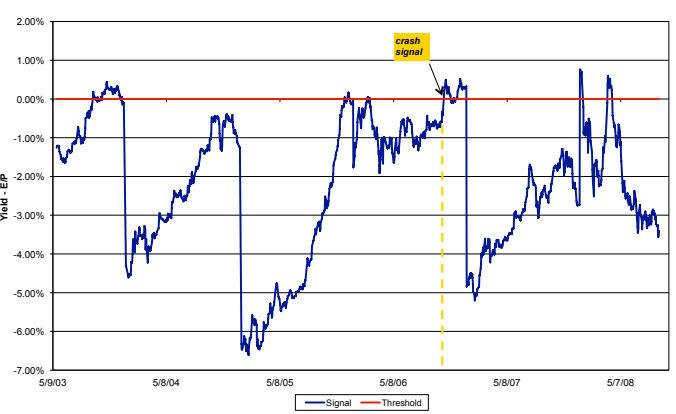

(b) Glitnir, MACI

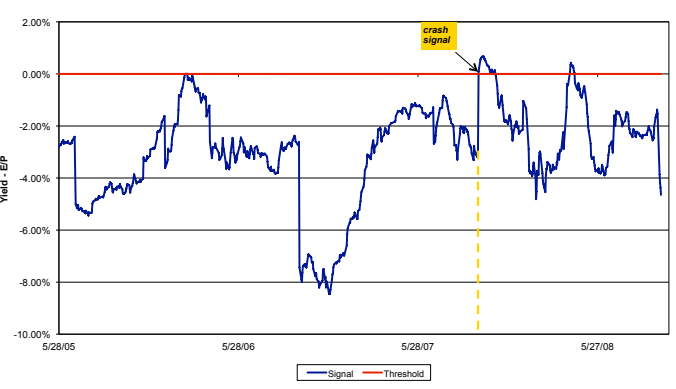

(d) Kaupthing, MACI

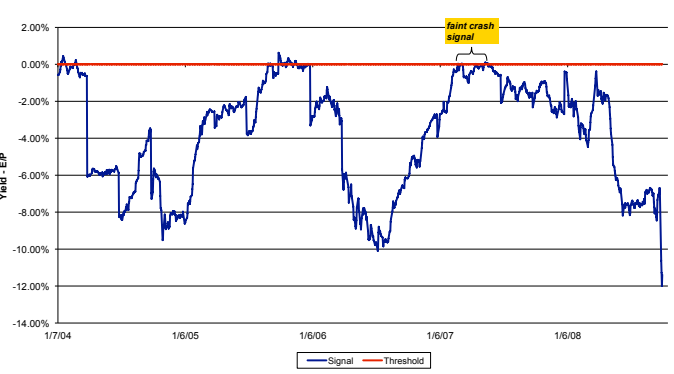

(f) Lansbanki, MACI

Figure 25: Crash Signals, Iceland 


\section{The crash of China's Shanghai stock index}

Figure 26 shows the rise of the Shanghai stock index from January 4, 2000 to February 25, 2014. The market bottomed at 1011 on July 11, 2005. It then rose six-fold to peak at 6092 on October 16, 2007. Then there was a crash of $11.98 \%$ to from 5180 to 4560 on January 21 and 22 followed by another $7.19 \%$ fall from 4762 to 4419 on January 28, 2008.

Shanghai Stock Exchange Composite (January 4, 2000 to February 25, 2014)

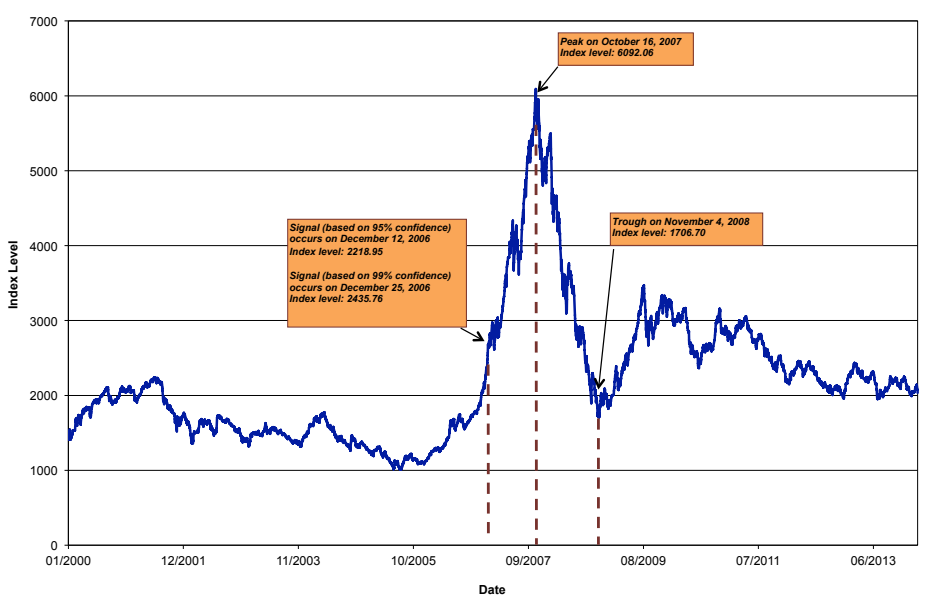

Figure 26: The Shanghai stock exchange composite index, January 2000 to February 25, 2014

Did the BSEYD model predict this crash? First, Figure 27 shows that the BSEYD measure is not normally distributed with fat right and especially left tails. The biggest declines are larger than the biggest increases.

Figures 28 and 29 show that the model did in fact predict the crash. It is a typical application of the model. The signal goes into the danger zone, then the market continues higher but within four to twelve months there is a crash of $10 \%+$ from the initial signal. In this case, the decline is much higher than $10 \%$. Figure 28 uses a $95 \%$ confidence one sided moving average interval using prior data out of sample. The danger signal occurs on November 12, 2006, some eleven months before the stock market peak on October 16 , 2007. Figure 29 uses a $99 \%$ one sided confidence interval and gives the first danger signal on June 29, 2007, with the index at 3821. The market reached its peak on October 16, 2007. 
Figure 27: Spread distribution of the BSEYD measure on the Shanghai Stock Exchange Composite

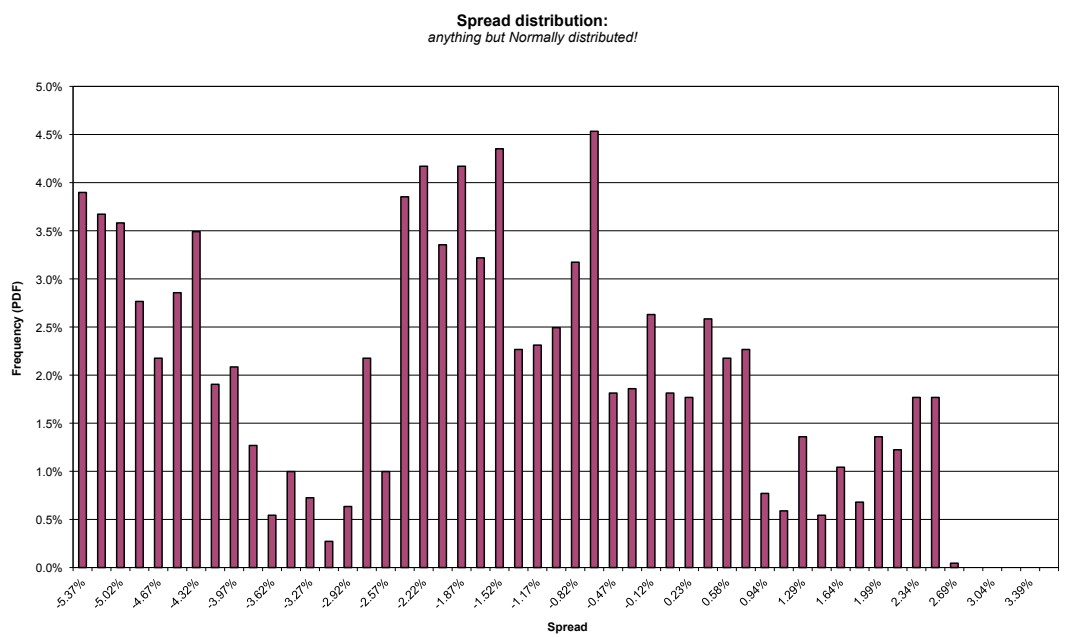

Figure 28: BSEYD crash indicator (95\% one sided moving average confidence): Shanghai Stock Exchange Composite

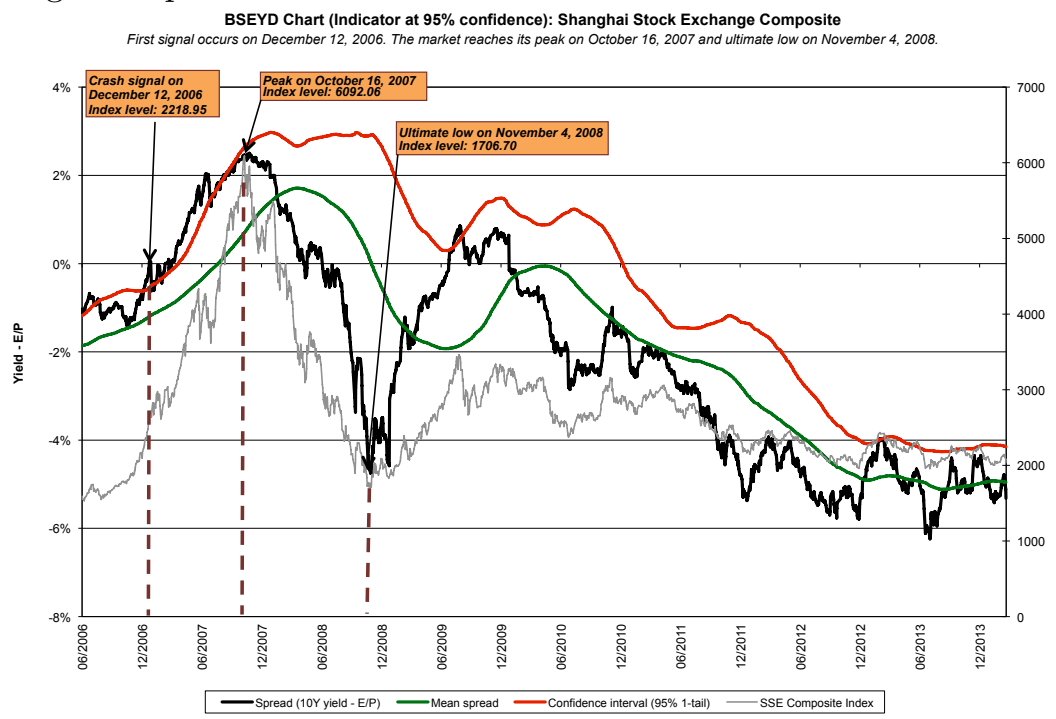


Table 14: Highlights on the Shanghai Stock Index, 2005-2013

\begin{tabular}{|c|c|c|}
\hline Date & Index Value & Comment \\
\hline Dec 31,2004 & 1266.50 & \\
\hline May 23, 2005 & 1070.84 & The index was down $15.4 \%$ year-to-date \\
\hline July 11, 2005 & 1011.50 & Market bottom \\
\hline Dec 31,2005 & 1161.06 & The index was down $8.3 \%$ in 2005 \\
\hline Dec 12,2006 & 2218.95 & $95 \%$ confidence BSEYD crash signal occurs \\
\hline Dec 25,2006 & 2435.76 & $99 \%$ confidence BSEYD crash signal occurs \\
\hline Dec 31,2006 & 2675.47 & The index was up $130.4 \%$ in 2006 \\
\hline May 29, 2007 & 4334.92 & Local high of the market. The market was up $62 \%$ year-to-date \\
\hline July 5, 2007 & 3615.87 & Local low of the market. The market was still up $35.1 \%$ year-to-date \\
\hline Oct 16,2007 & 6092.06 & Highest historical market close. The market was up $127.7 \%$ year-to-date \\
\hline Nov 28,2007 & 4803.39 & Local low of the market. The market was still up $79.5 \%$ year-to-date \\
\hline Dec 31, 2007 & 5261.56 & Index was up $96.7 \%$ in 2007 , but down $13.6 \%$ from its peak in October \\
\hline Jan 14,2008 & 5497.90 & Local high of the market \\
\hline Jan 18,2008 & 5180.51 & $\begin{array}{l}\text { The index closes the week at } 5180.51 \text {, } \\
\text { which is } 5.8 \% \text { lower than than its local high on Jan } 14\end{array}$ \\
\hline Jan 21,2008 & 4914.43 & The index experiences a one-day drop of $5.1 \%$ from 5180.51 to 4914.43 \\
\hline Jan 22,2008 & 4559.75 & $\begin{array}{l}\text { The index experiences declines by } 7.2 \% \text { on this day, } \\
\text { opening at } 4914.43 \text { to close at } 4559.75\end{array}$ \\
\hline Jan 25,2008 & 4761.69 & The index recovers slightly to close the week at 4761.69 \\
\hline $\operatorname{Jan} 28,2008$ & 4419.29 & The index drops by $7.2 \%$ from 4761.69 to 4419.29 \\
\hline Apr 18,2008 & 3094.67 & Local low of the market \\
\hline May 5, 2008 & 3761.01 & Local high of the market \\
\hline Nov 4,2008 & 1706.70 & $\begin{array}{l}\text { Global market minimum. The market was down by } 72 \% \text { peak to trough } \\
\text { and } 23.09 \% \text { and } 29.93 \% \text { from the December } 12 \text { and } 25 \text { danger signal levels }\end{array}$ \\
\hline Dec 31,2008 & 1820.81 & The market was down $65.4 \%$ in 2008 \\
\hline Aug 3, 2009 & 3471.44 & Local high of the market. The market was up $103.4 \%$ from the trough \\
\hline Aug 31, 2009 & 2667.75 & Local low of the market \\
\hline Nov 23, 2009 & 3338.66 & Local high of the market \\
\hline Dec 31, 2009 & 3277.14 & The market was up $80 \%$ in 2009 \\
\hline Jul 5, 20100 & 2363.95 & Local low of the market \\
\hline Dec 31, 2010 & 2808.08 & The market was down $14.3 \%$ in 2009 \\
\hline Jun 30,2011 & 2762.08 & The market was down about $1 \%$ year-to-date \\
\hline August 31, 2011 & 2567.34 & The market was down about $8.6 \%$ year-to-date \\
\hline September 30, 2011 & 2359.22 & The market was down about $16 \%$ year-to-date \\
\hline December 31, 2011 & 2199.42 & The market was down $6.8 \%$ in 2011 \\
\hline December 31, 2012 & 2269.13 & The market was up $3.2 \%$ in 2012 \\
\hline December 31, 2013 & 2115.98 & The market was down $6.7 \%$ in 2013 \\
\hline
\end{tabular}


Figure 29: BSEYD crash indicator (99\% one-sided moving average confidence): Shanghai Stock Exchange Composite

BSEYD Chart (Indicator at 99\% confidence): Shanghai Stock Exchange Composite

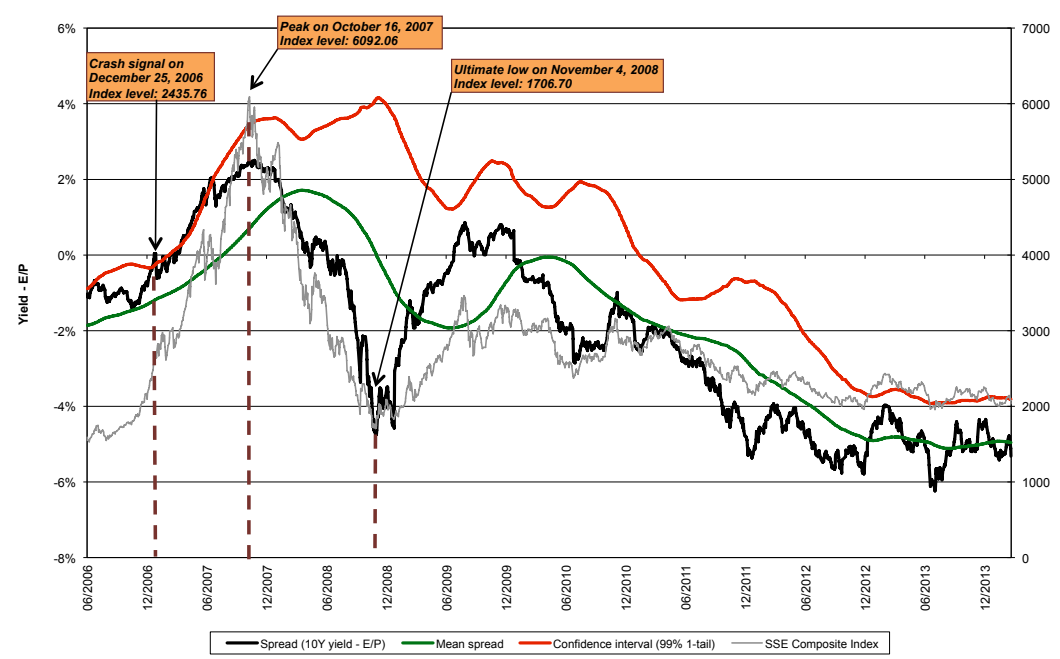




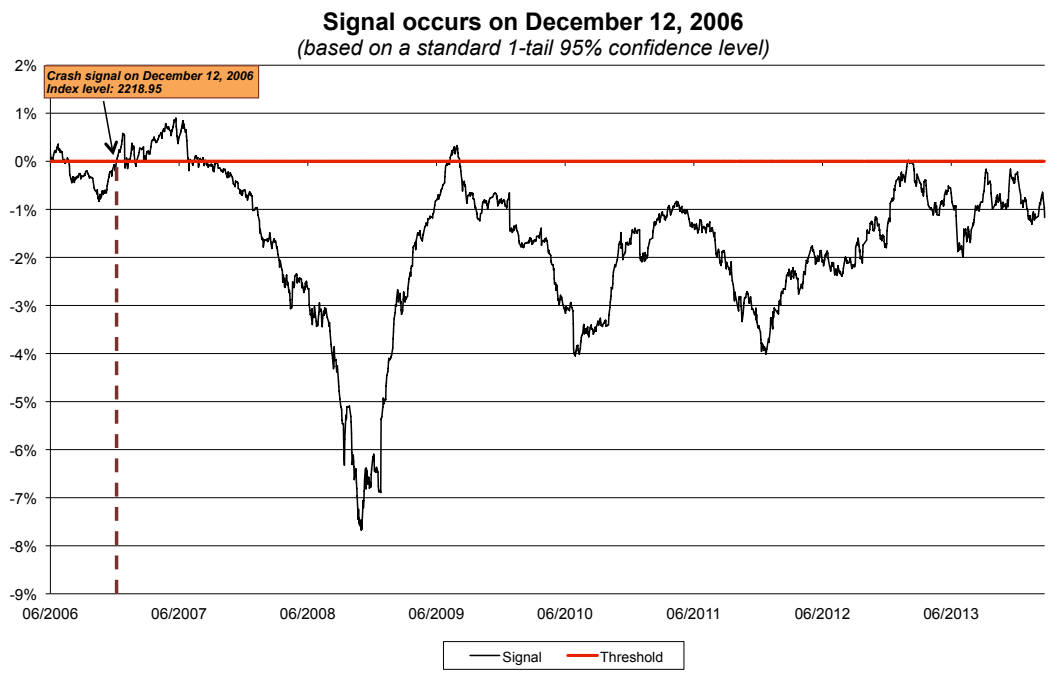

(a) Signal occurs on December 12, 2006 based on $95 \%$ confidence

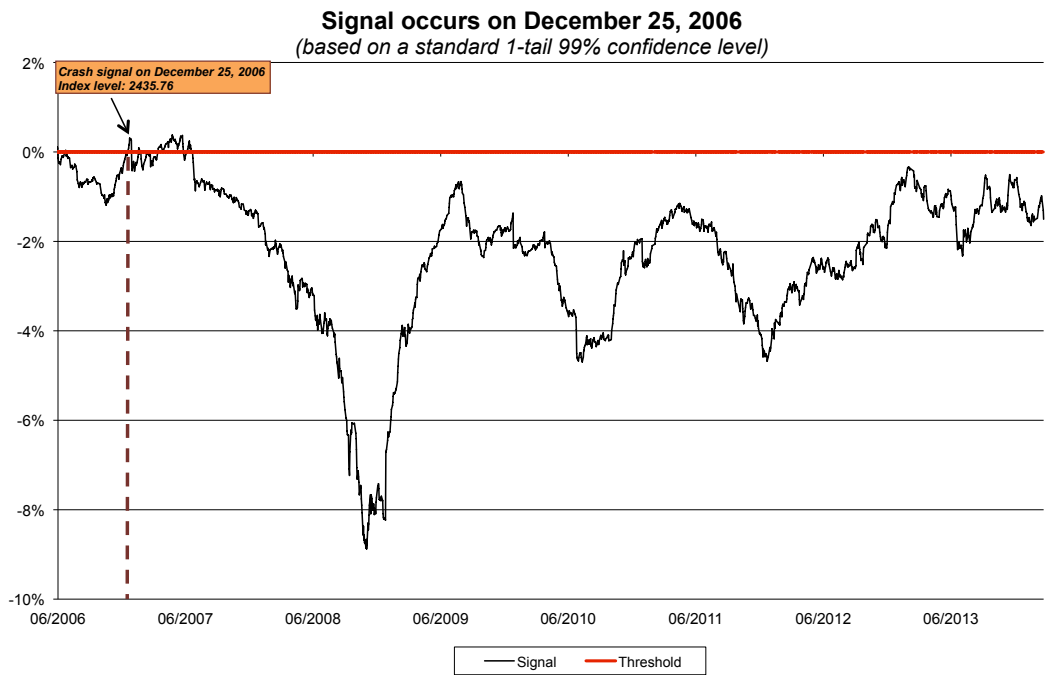

(b) Signal occurs on December 25, 2006 based on 99\% confidence

Figure 30: BSEYD danger signals for the Shanghai Stock Exchange Composite, Signals at $95 \%$ and $99 \%$ confidence 


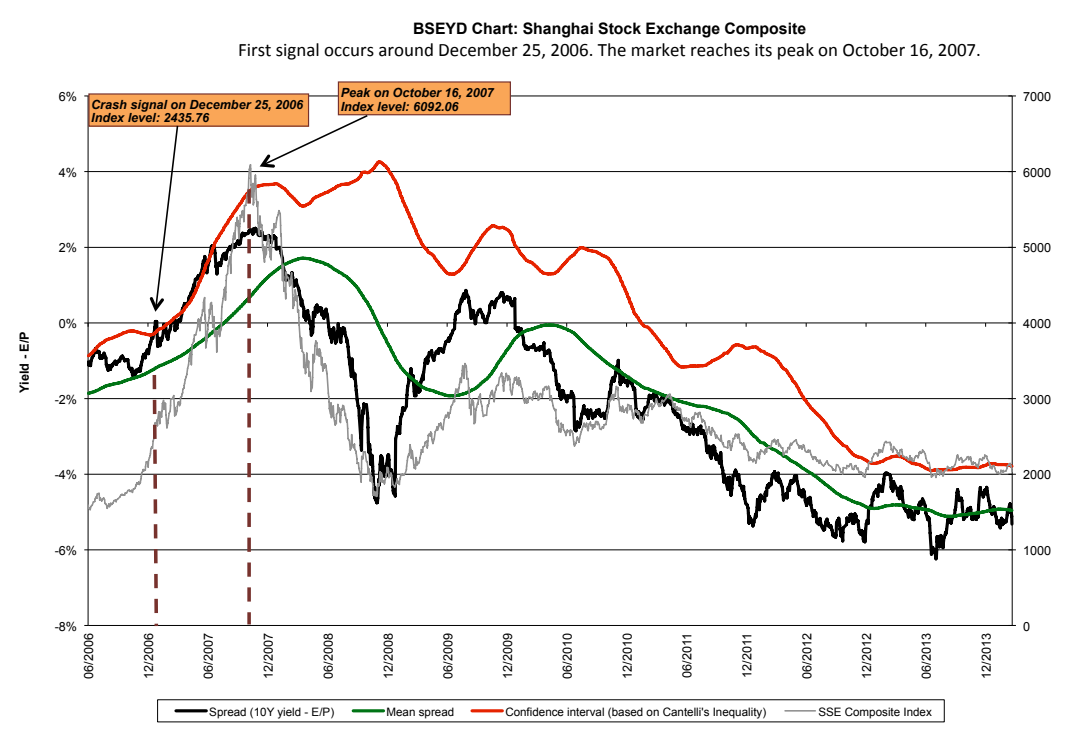

(a) First signal occurs on December 25, 2006. The market reaches its peak on October 16, 2007.

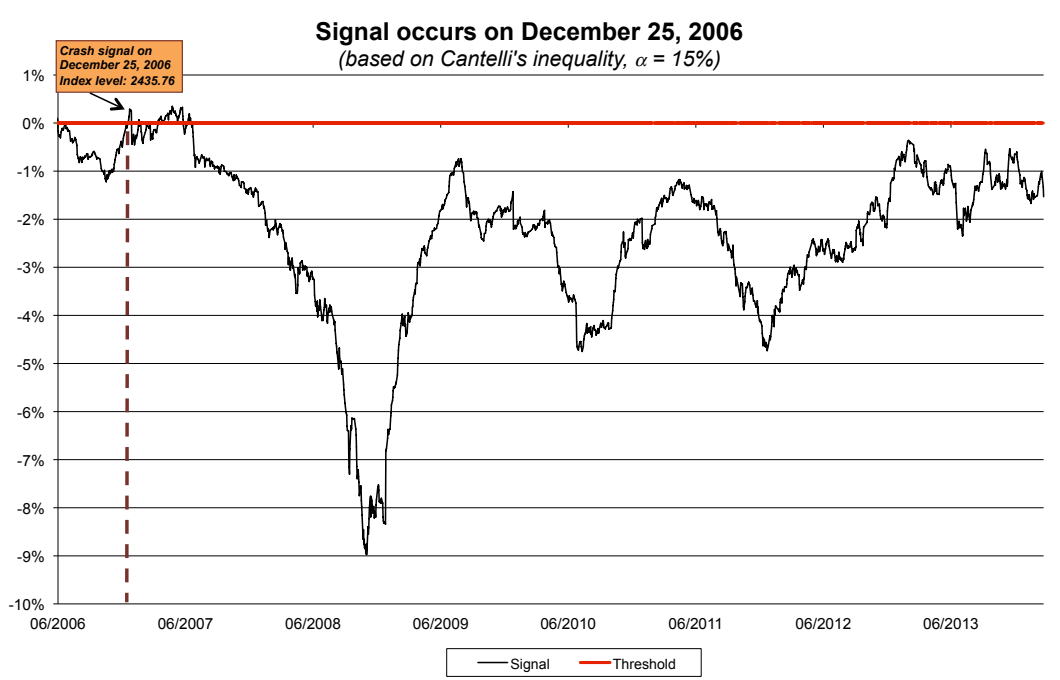

(b) Signal occurs on December 25, 2006 (based on Cantelli's inequality, $\alpha=$ $15 \%)$

Figure 31: BSEYD Cantelli danger signals for the Shanghai Stock Exchange Composite 


\section{The US 2007-2009 crash}

In this section we investigate whether or not the bond-stock measure did predict the US 2007-2009 crash, specifically the September 2008 to March 2009 period. Table 9 shows the BSEYD at various periods. In 2006 the weak economy led the Fed to dramatically reduce short term interest rates which tended to drop the long term rates that we use in the BSEYD calculations. Ex post it is clear that this stock market crash had a lot of components such as the first decline in US housing prices n more than thirty years, a subprime market collapsing because home buyers could not cover their mortgages, lots of suspect AAA rated packages of these mortgages and then a credit squeeze with much counterparty risk with firms unwilling to lend money to others including supposedly sound financial institutions and the collapse of many large and previously sound financial institutions such as Bear Stearns, AIG, Freddy Mac, Fannie May and the killer for the market, Lehman Brothers.

There are numerous books concerning this period plus many articles and columns, even I have several in Wilmott. Starting in June 2007, I designed strategies and traded for an offshore BVI based hedge fund for a group headed by a top trader. He had investments in Bear Stearns and in June 2007 asked for his money back. That took three months and gave him a strong signal of danger. As an astute trader, he hedged and studied carefully the market situation through technical indicators that he has developed. I remember his words to me starting in the summer of 2007 "this is the big one" ... "eventually the market will go to 666 on the S\&P500". In the fall of 2007 the S\&P500 was about 1550, see Table 32. So this was a rather bold call but a private one and it turned out to be very accurate. Rachel Ziemba was working in New York for Nouriel Roubini's company, Roubini Global Economics and he was predicting very boldly a serious financial meltdown starting in 2006 when the housing market was beginning its decline; see Figure 33 which gives the Case Shiller Home Price Index as of July 24, 2008. We see a sharp decline from 2005 to 2008. As of April 2011, he and other bears such as Yale Professor Robert Shiller were still pessimistic about the economy, real estate and financial markets. Dropping real estate has several depressive effects such as homeowners can no longer use house price gains to fund consumption, foreclosures, etc. The March 2009 low was 660 and the subsequent rally has doubled the S\&P500 to the 1330 area at the beginning of April 2011 then to the 1840 area in February 2014. There is lots of discussion regarding whether or not this rally is low interest rate related to the Fed quantitative easing, or only game in town since real estate, bonds and cash look unattractive. This is a case when the BSEYD signaled the rise in stock prices.

Lets go back to the BSEYD and consider Table 15 which was published in the Maudlin weekly newsletter on 2008, and discuss whether or not it called the September 2008 to March 2009 crash.

First though, lets look at the measure across the world on July 12, 2006 in Table 9. 
S\&P 500 Index

25, 2014)

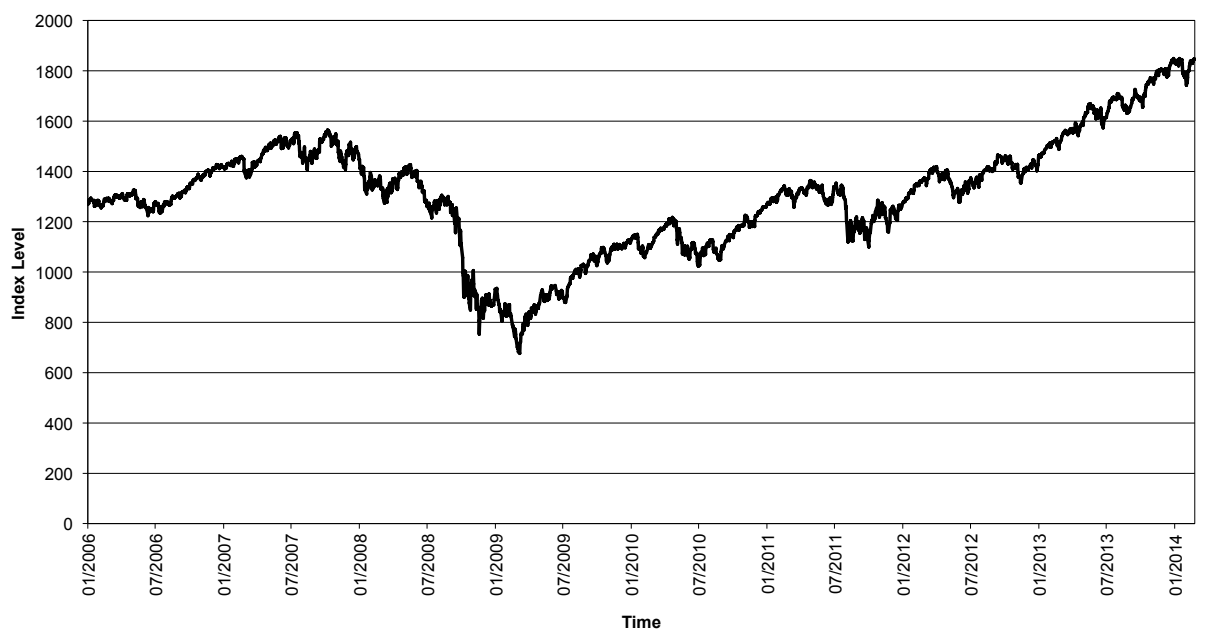

Figure 32: The S\&P500, January 1, 2006 to february 25, 2014

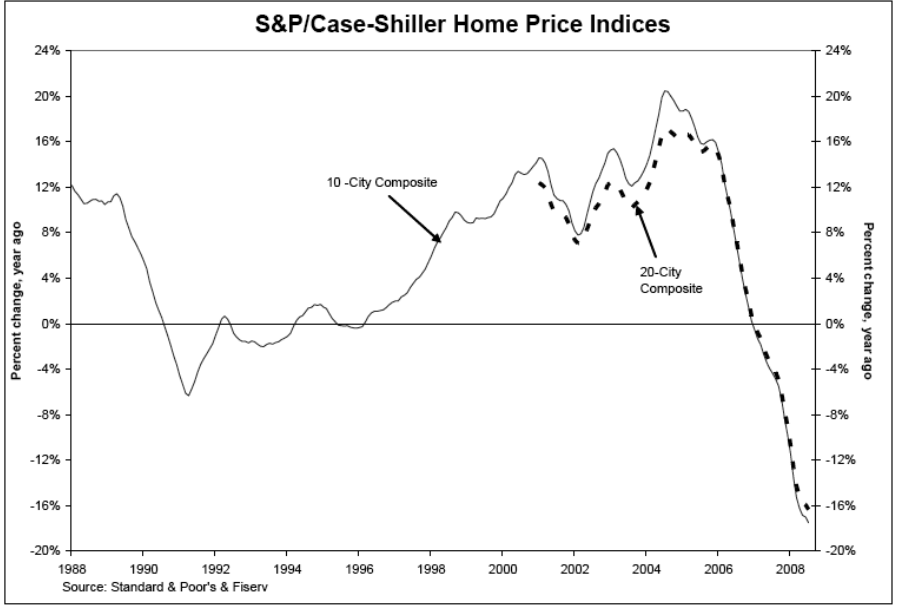

Figure 33: Case Shiller Index as of July 29, 2008. 
We see that none of these major markets were in the danger zone then. Figures 34ab show the S\&P500 PE ratios (Shiller's calculation method) and the ten-year Treasury bond yield.

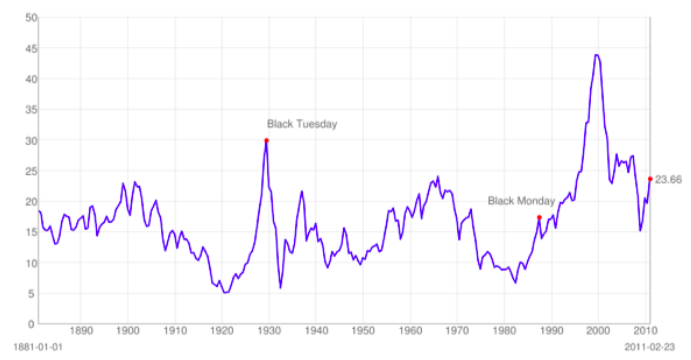

(a) S\&P500 price earnings ratios

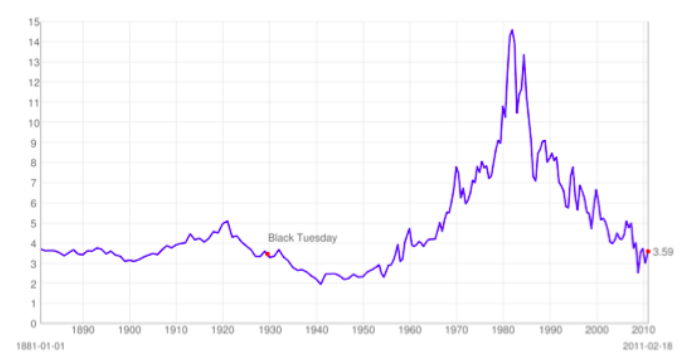

(b) Treasury bond yield

Figure 34: S\&P500 and ten-year Treasury bond yields. Source: Robert Shiller data.

Table 15: Earnings revisions for 2008 and 2009, analysts estimates of earnings in dollars. Source: Maudlin,2008

\begin{tabular}{lr|lr} 
Date & Earnings & Date & Earnings \\
March 2007 & 92.00 & March 20, 2008 & 81.52 \\
December 2007 & 84.00 & April 9, 2008 & 72.60 \\
February 2008 & 71.20 & June 25, 2008 & 70.13 \\
June 1, 2008 & 68.93 & September 10, 2008 & 48.52 \\
July 25, 2008 & 72.00 & August 29, 2008 & 64.44 \\
September 30, 2008 & 60.00 & February 1, 2009 & 42.00 \\
October 15, 2008 & 54.82 & February 20, 2009 & 32.41 \\
February 20, 2009 & 26.23 & April 10, 2009 & 28.51 \\
April 10, 2009 & 14.88 & &
\end{tabular}

Table 15 has the S\&P500 2008 estimated earnings and 2009 forecasted earnings. On July 25, 2008, the S\&P500 earnings for 2008 were estimated to be 72.00 with the S\&P500 at 1257.76 which gives a PE ratio of 17.47 which is not high enough to signal the September 2008 to March 2009 crash. But by February 20, 2009, the 2008 earnings were estimated to be 26.23 . With the S\&P500 at 770.05 on that day the PE ratio was 29.36 which gives a BSEYD value of $3.81 \%$, with the ten year Treasury bond yielding $2.78 \%$. This is in the danger zone but a rather late call.

Shepherd (2008) has the S\&P500 PE ratio at 723! So what did I conclude here? Well let's 
go with the BSEYD model which had a crash call on June 14, 2007 and no such call after that going into 2014 .

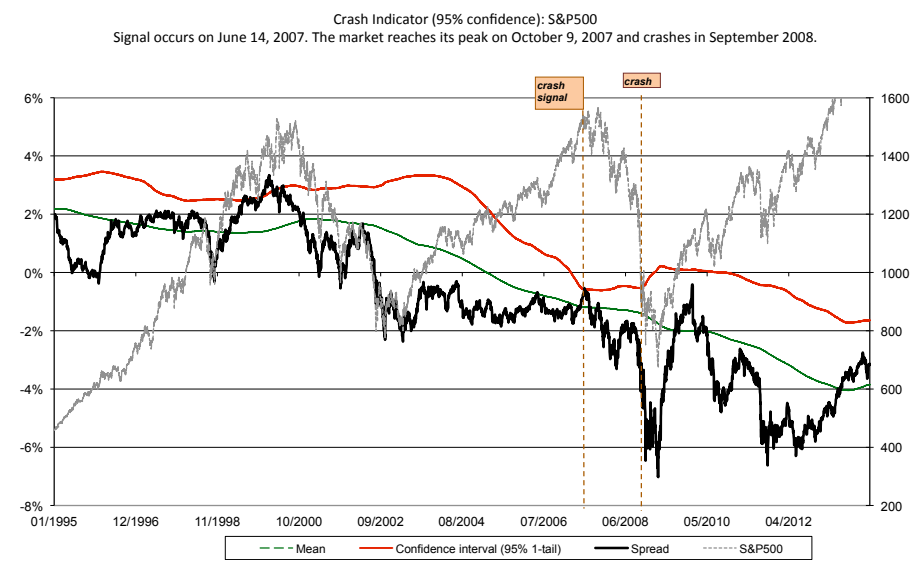

(a) Crash Indicator (95\% confidence): S\&P500 MA

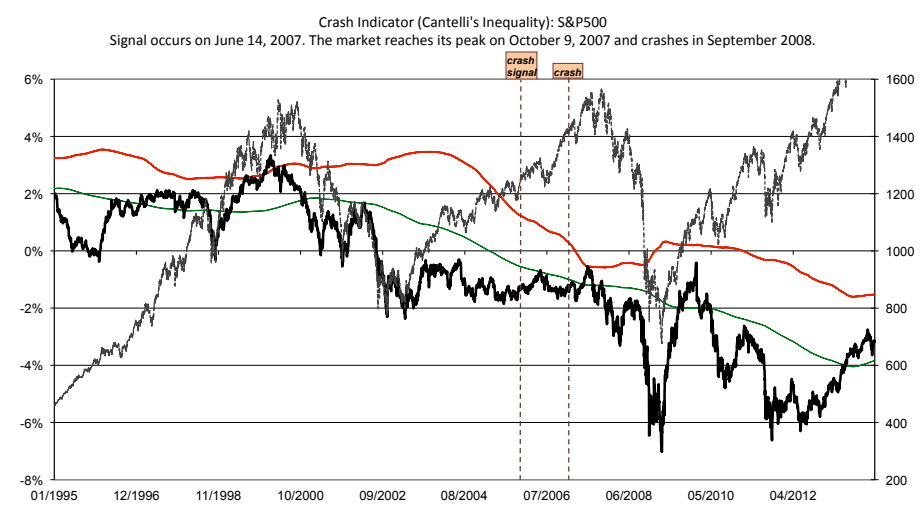

(b) Crash Indicator (Cantelli's Inequality): S\&P500, MACI

Figure 35: Crash Indicators, show June 14, 2007 signal 

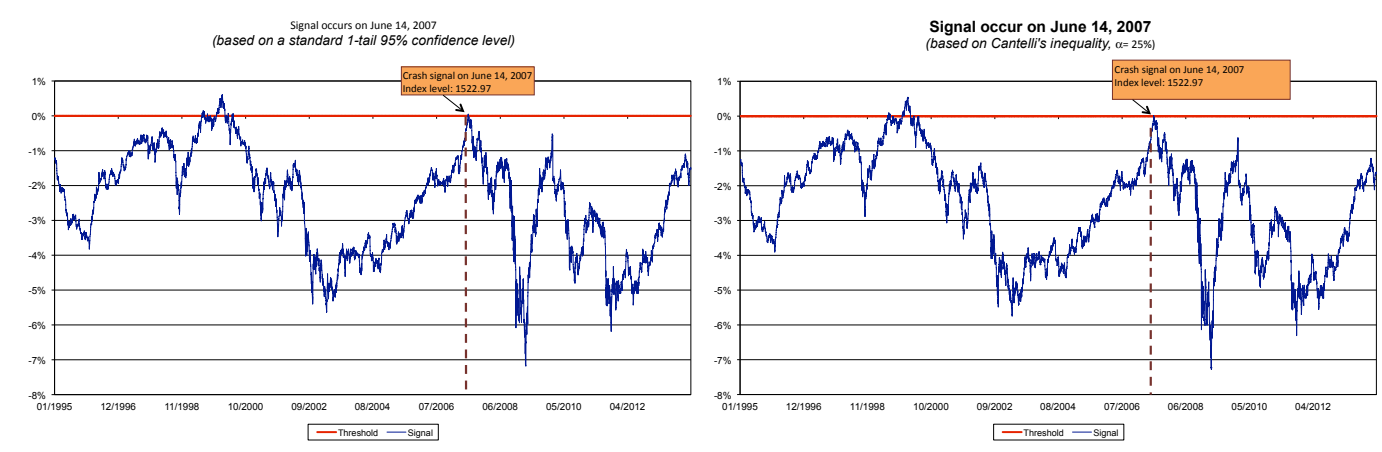

(a) Based on a standard 1-tail 95\% confidence level, (b) Based on a standard 1-tail 95\% confidence level, MA

Figure 36: Signal occurs on June 14, 2007

Figure 37: Spread distribution of the BSEYD measure on the S\&P500.

Spread distribution:

anything but Normally distributed!

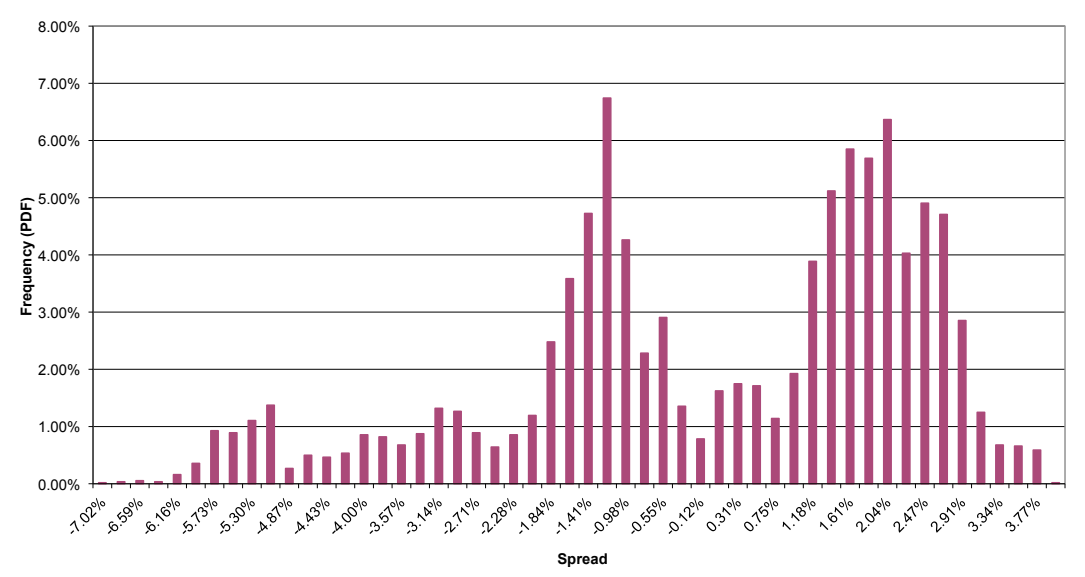


Table 16: Highlights of the S\&P500, January 1, 2006 to December 31, 2013

\begin{tabular}{|c|c|c|}
\hline Date & Index Value & Comment \\
\hline December 31, 2005 & 1248.29 & \\
\hline August 31,2006 & 1303.82 & Gain of $4.4 \%$ year-to-date \\
\hline December 31, 2006 & 1418.30 & Gain of $13.6 \%$ in 2006 \\
\hline February 26, 2007 & 1437.50 & Local high of market \\
\hline March 1, 2007 & 1374.12 & Local low of market \\
\hline June 7,2007 & 1480.72 & Bear Stearns suspends redemptions from one of its hedge funds \\
\hline June 14,2007 & 1522.97 & BSEYD crash signal occurs \\
\hline July 13, 2007 & 1552.50 & Local high of market \\
\hline July 31,2007 & 1455.27 & Bear Stearns liquidates two hedge funds \\
\hline August 16, 2007 & 1411.27 & Local low of market \\
\hline October 9, 2007 & 1565.15 & Market peak. Gain of $10.4 \%$ year-to-date \\
\hline December 31, 2007 & 1468.35 & Gain of $3.5 \%$ in 2007 \\
\hline March 17, 2008 & 1276.60 & Local low of market \\
\hline September 15, 2008 & 1192.70 & Lehman Brothers files for bankruptcy protection \\
\hline September 30, 2008 & 1166.36 & Market down by $20.6 \%$ year-to-date \\
\hline October 10,2008 & 899.22 & Local low of market \\
\hline October 31,2008 & 968.75 & Market down by $16.9 \%$ in October \\
\hline December 31, 2008 & 903.25 & Market down by $38.5 \%$ in 2008 \\
\hline March 9, 2009 & 683.38 & Lowest intraday: 666.79. \\
\hline March 9, 2009 & 676.53 & Market trough. The market was down by $56.8 \%$ peak to trough \\
\hline July 28,2009 & 979.62 & $\begin{array}{l}\text { Date Shepherd claimed that the S\&P } 500 \text { had a } 723 \text { PE ratio } \\
\text { based on reported (real earnings) to the SEC on } 10 \mathrm{Q} \text { forms }\end{array}$ \\
\hline December 31, 2009 & 1115.10 & Market was down by $23.5 \%$ in 2009 , but up by $64.8 \%$ since trough \\
\hline April 23, 2010 & 1217.28 & Local high \\
\hline July 2,2010 & 1022.58 & Local low \\
\hline December 31, 2010 & 1257.64 & $\begin{array}{l}\text { Gain of } 12.8 \% \text { in } 2010 \text {, and of } 23 \% \\
\text { since the local low of July } 2,2010\end{array}$ \\
\hline May 10, 2011 & 1357.16 & $\begin{array}{l}\text { Local high. Gain of } 7.91 \% \text { year-to-date and of } 32.72 \% \\
\text { since the local low of July } 2,2010\end{array}$ \\
\hline August 31,2011 & 1218.89 & $\begin{array}{l}\text { Loss of } 3.1 \% \text { year-to-date and of } 10.2 \% \\
\text { since the local high of May } 10,2010\end{array}$ \\
\hline October 3, 2011 & 1099.23 & $\begin{array}{l}\text { Local trough. Loss of } 12.6 \% \text { year-to-date and of } 19 \% \\
\text { since the local high of May } 10,2010\end{array}$ \\
\hline December 31, 2011 & 1257.60 & $\begin{array}{l}\text { The S\&P500 ends } 2011 \text { flat. Loss of } 7.4 \% \\
\text { since the local high of May } 10,2010\end{array}$ \\
\hline December 31, 2012 & 1426.19 & Gain of $13.4 \%$ in 2012 \\
\hline December 31, 2013 & 1848.36 & Gain of $29.6 \%$ in 2013 \\
\hline
\end{tabular}




\section{How accurate is the BSEYD as crash prediction model?}

Lleo and Ziemba (2014b) test statistically the predictive ability of the BSEYD model on a fifty-one year period starting January 1, 1962 and ending December 31, 2012 (12,846 daily data). The methodology is based on a standard Likelihood Ratio test conducted on a 'hit sequence' derived from the time series of signal. This approach is akin to the run tests used to determine whether a coin is fair. The methodology is complemented by a Monte Carlo study for small sample bias and by an analysis of the robustness of the measure. In this section, we highlight some of the key results and refer the interested reader to the paper for a detailed description of the methodology and a full discussion of the results.

Table 17 shows that between January 1, 1962 and December 31, 2012 the S\&P 500 Index experienced eighteen crashes, defined as a decline of at least $10 \%$ form the previous peak in less than one year. The three largest crashes were respectively a $52 \%$ decline from peak to trough in 2007-2008, a 37\% decline in 2000-2001 and a 36\% decline in 1968-1970. Overall, seven crashes exceeded $20 \%$ and 13 exceeded $15 \%$.

What is the track record of the BSEYD model? Table 18 shows the BSEYD model based on a standard confidence interval went into the danger zone on 39 distinct instances. The prediction proved correct on 28 instances, giving a $72 \%$ accuracy. The number of predictions is higher than the number of actual crashes because several distinct crash signals may precede the same crash. This was the case for example in 1969, when the BSEYD model produced four distinct signals on June 6, 1967, May 31, 1968, November 18, 1968 and May 25, 1969. The locals peak was reached on November 29, 1968. By June 20, 1969 the market had declined $10 \%$ within a year. The trough was eventually reached on May 26, 1970. This case is illustrated in Figure 38.

The observations for the BSEYD model based on Cantelli's inequality are similar: the model had 26 correct prediction out of 37 signals, a $70 \%$ accuracy.

Table 19 shows the results of the statistical test. The maximum likelihood estimate of the signal $\hat{p}$ in column 2 equals the historical accuracy of the models displayed in Table 18. The likelihood ratio $\Lambda$ in Column 3 is the ratio of the likelihood under the null hypothesis that the BSEYD predictions are purely random, to the likelihood using the estimated probability $\hat{p}$. The estimated test statistics, equal to $-2 \ln \Lambda$, is asymptotically $\chi^{2}$-distributed with 1 degree of freedom. The $p$-value is the probability of obtaining a test statistic higher than the one actually observed, assuming that the null hypothesis is true. The degree of significance and the $p$-value indicated in the table are both based on the 


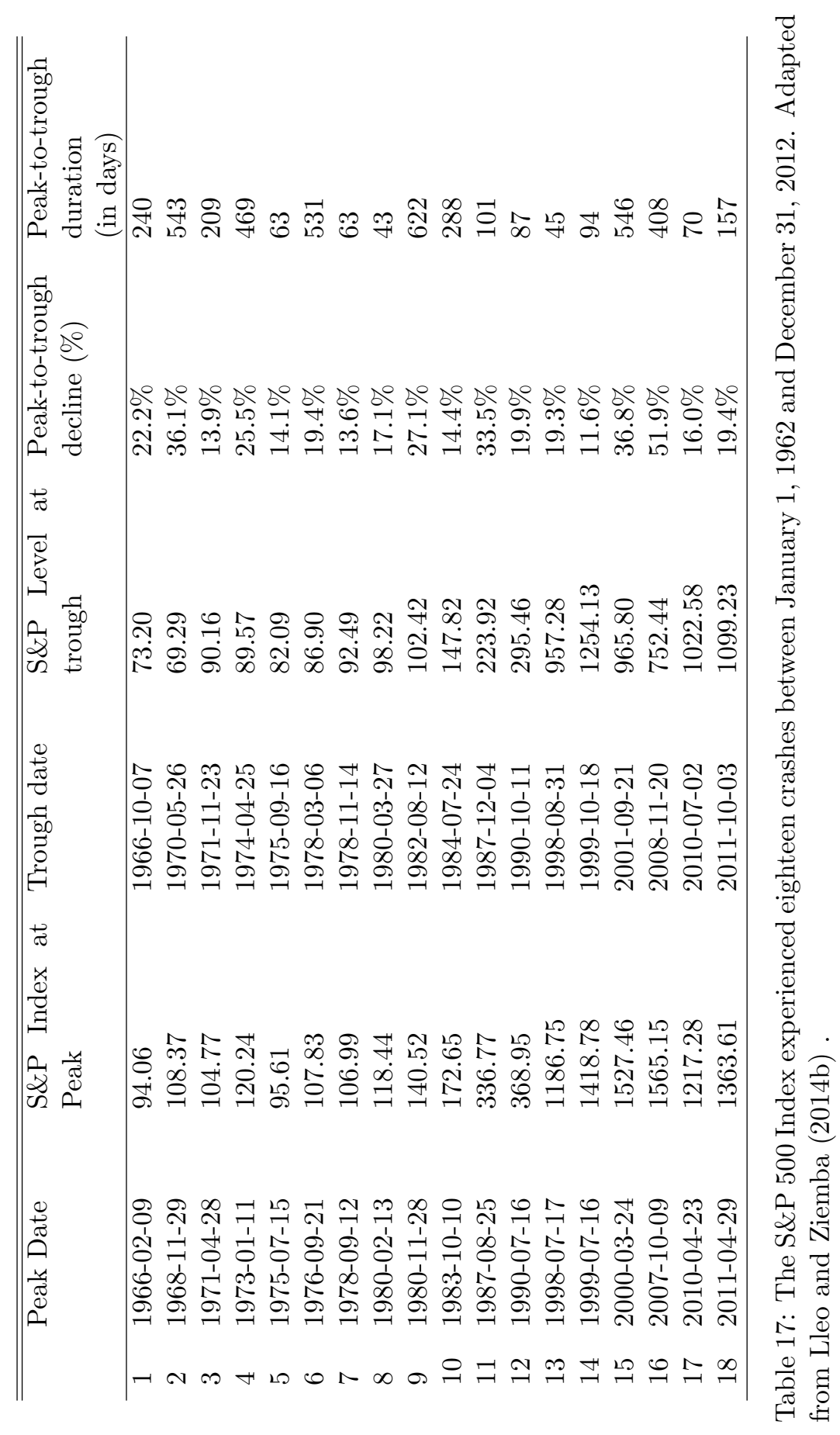


Four distinct signals preceded the June 20, 1969 crash (Model BSEYD1)

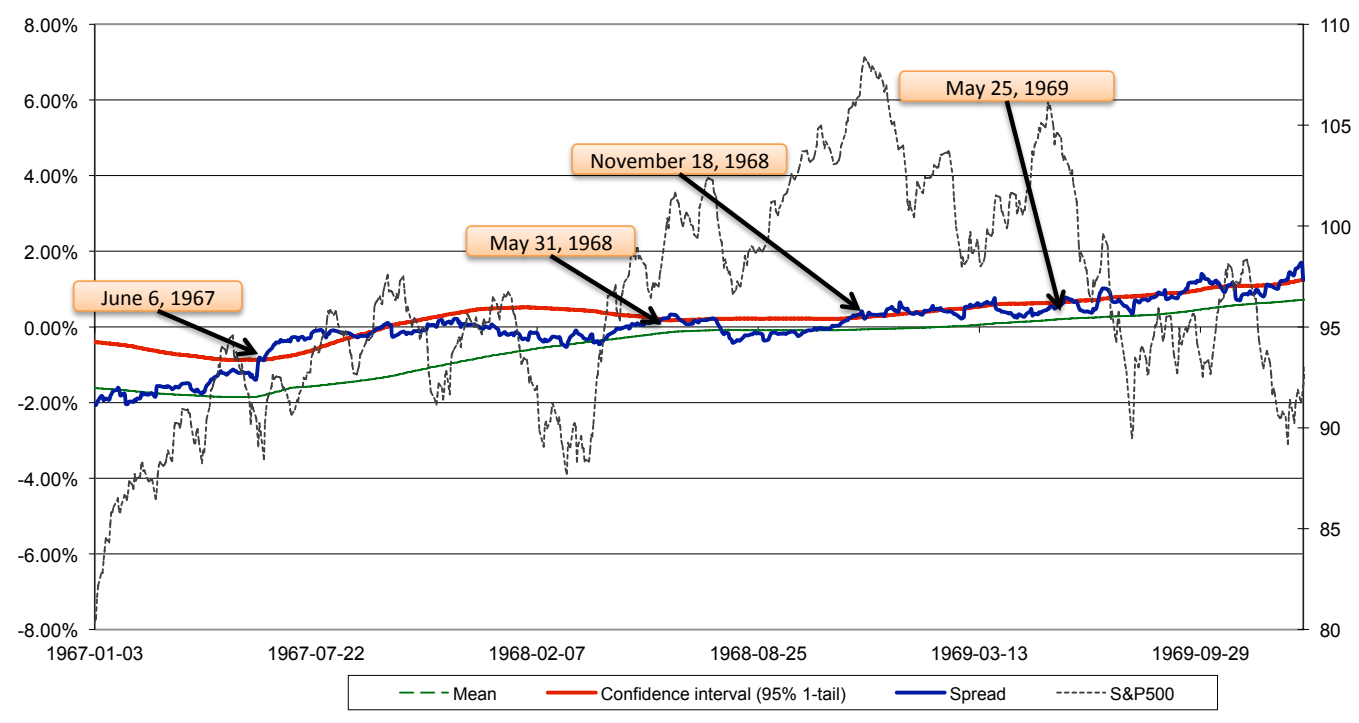

Figure 38: Four Positive Signals Preceded the 1969 Equity Market Crash. Source: Lleo and Ziemba (2014b) 


\begin{tabular}{llll}
\hline $\begin{array}{l}\text { Signal } \\
\text { Model } \\
(1)\end{array}$ & $\begin{array}{c}\text { Total number } \\
\text { of signals } \\
(2)\end{array}$ & $\begin{array}{l}\text { Number of correct } \\
\text { predictions } \\
(3)\end{array}$ & $\begin{array}{l}\text { Proportion of correct } \\
\text { predictions (\%) } \\
(4)\end{array}$ \\
\hline Standard & 39 & 28 & $71.79 \%$ \\
Cantelli & 37 & 26 & $70.27 \%$ \\
\hline
\end{tabular}

Table 18: Proportion of Correct and Incorrect Predictions for Each Signal Model

\begin{tabular}{|c|c|c|c|c|c|}
\hline $\begin{array}{l}\text { Signal } \\
\text { Model }\end{array}$ & $\begin{array}{l}\text { ML } \\
\text { Estimate } \\
\hat{p}\end{array}$ & $L(\hat{p})$ & $\begin{array}{l}\text { Likelihood } \\
\text { ratio } \Lambda\end{array}$ & $\begin{array}{l}\text { Test statistics } \\
-2 \ln \Lambda\end{array}$ & $p$-value \\
\hline Standard & $71.79 \%$ & 8.3989E-11 & 0.0217 & $7.6648^{* *}$ & $0.56 \%$ \\
\hline Cantelli & $70.27 \%$ & $1.6640 \mathrm{E}-10$ & 0.0437 & $6.2597^{*}$ & $1.24 \%$ \\
\hline
\end{tabular}

* significant at the $95 \%$ level.

** significant at the $99 \%$ level.

Table 19: Maximum Likelihood Estimate and Likelihood Ratio Test

$\chi^{2}$-distribution with 1 degree of freedom. The critical values at the $95 \%, 99 \%$ and $99 \%$ level are respectively 3.8415, 6.6349 and 7.8794. Observe that the BSEYD measure based on a standard confidence interval is significant at a $99 \%$ confidence level and the BSEYD model based on Cantelli's inequality is not far from the 99\% mark. The null hypothesis that the BSEYD predictions are purely random can be rejected: the BSEYD has an ability to predict crashes over a one to two year horizon.

In addition to testing 8 choices of parameters for the BSEYD model, Lleo and Ziemba (2014b) also tested the predictive ability of the logarithm of the BSEYD, the P/E ratio and the logarithm of the $\mathrm{P} / \mathrm{E}$ ratio. They found that historically the original BSEYD model and its logarithmic version have shown a higher predictive ability than the $\mathrm{P} / \mathrm{E}$ ratio. Among the models tested, the logarithm of the $\mathrm{P} / \mathrm{E}$ ratio showed the least consistency and robustness. 


\section{References}

Berge, K., G. Consigli, and W. T. Ziemba (2008). The predictive ability of the bond stock earnings yield differential. Journal of Portfolio Management (Spring), 63-80.

Berge, K. and W. T. Ziemba (2003). The predictive ability of bond versus stock earnings yield differences. Working paper, Faculty of Commerce, University of British Columbia.

Bertocchi, M., S. L. Schwartz, and W. T. Ziemba (2010). Optimizing the aging, retirement and pensions dilemma. Wiley.

Buffett, W. B. (2001). Warren Buffett on the stock market. Fortune, December 10.

Campbell, J. Y. and R. J. Shiller (1988). Stock prices, earnings, and expected dividends. Journal of Finance 43(3), 661-676.

Campbell, J. Y. and R. J. Shiller (1998). Valuation ratios and the long-run stock market outlook. Journal of Portfolio Management 24, 11-26.

Campbell, J. Y. and R. J. Shiller (2001). Valuation ratios and the long-run stock market outlook: on update. Working paper W8221, NBER.

Corcos, A., J.-P. Eckmann, A. Malaspinas, and Y. Malevergne (2002). Imitation and contrarian behaviour: hyperbolic bubbles, craches and chaos. Quantitative Finance 2, $264-281$.

Estrada, J. (2006). The Fed model: A note. Financial Research Letters 3, 14-22.

Faugère, C. (2013, August). The fear premium and daily comovements of the s\&p 500 $\mathrm{E} / \mathrm{P}$ ratio and treasury yields before and during the 2008 financial crisis. Financial Markets, Institutions 6 Instruments 22(3), 171-207.

Faugère, C. and J. Van Erlach (2009, February). A required yield theory of stock market valuation and treasury yield determination. Financial Markets, Institutions $\&$ Instruments 18(1), 27-88.

Giot, P. and M. Petitjean (2008). Short-term market timing using the bond-equity yield ratio. European Journal of Finance (April-June), 365-384.

Glitner (2006). List of available funds, May.

Gordon, M. J. (1959). Dividends, earnings and stock prices. Review of Economics and Statistics 41(2), 99-105.

Grimmett, G. and D. Stirzaker (2001). Probability and Random Processes. Oxford University Press.

IIbbotson Associates (1999). Stocks, bonds, bills and inflation, 1999 Year Book. Ibbotson Associates, Chicago.

Jacobs, B. I. and K. N. Levy (1988). Disentangling equity return regularities: new insights and investment opportunities. Financial Analysts Journal 44, 47-62.

Jarrow, R., Y. Kohia, and P. Protter (2011). How to detect an asset bubble. SIAM Journal of Financial Math 2, 839-865.

Kallberg, J. G. and W. T. Ziemba (1983). Comparison of alternative utility functions in portfolio selection problems. Management Science 29(11), 1257-1276. 
Kindleberger, C. and R. Aliber (2011). Mainias, panics and crashes (6 ed.).

Koivu, M., T. Pennanen, and W. T. Ziemba (2005). Cointegration analysis of the fed model. Finance Research Letters 2, 248-256.

Lleo, S. and W. T. Ziemba (2012). Stock market crashes in 2007-2009: were we able to predict them? Quantitative Finance 12(8), 1161-1187.

Lleo, S. and W. T. Ziemba (2014a). Does the bond-stock earning yield differential model predict equity market corrections better than high P/E models? Working Paper, NEOMA Business School.

Lleo, S. and W. T. Ziemba (2014b). How to lose money in derivatives: examples from hedge funds and bank trading departments. In Mallaris and Ziemba (Eds.), Handbook of Futures Markets. World Scientific.

Maio, P. (2013). The fed model and the predictability of stock returns. Review of Finance 17, 1489-1533.

Maudlin (2008). Thoughts from the frontline.

Montier, J. (2011). The seven immutable laws of investing. in John Mauldin's Outside the Box, March 11.

Reinhart, C. M. and K. S. Rogoff (2009). This Time is Different: Eight Centuries of Financial Folly. Princeton University Press.

Schroder (2002). Schroder investment management ltd.

Schwartz, S. L. and W. T. Ziemba (2000). Predicting returns on the Tokyo stock exchange. In D. B. Keim and W. T. Ziemba (Eds.), Security Market Imperfections in World Wide Equity Markets, pp. 492-511. Cambridge University Press.

Shepherd, C. (2008). S\&P500 ratio is now at 723. www.trendinvestor.info.

Shiller, R. (2000). Irrational Exuberance. Princeton University Press.

Shiryaev, A. N., M. V. Zhitlukhin, and W. T. Ziemba (2014a). Land and stock bubbles, crashes and exit strategies in Japan circa 1990 and in 2013. Quantitative Finance (in press).

Shiryaev, A. N., M. V. Zhitlukhin, and W. T. Ziemba (2014b). When to sell Apple and the Nasdaq? Trading bubbles with a stochastic disorder model. Journal of Portfolio Management 40(2), 54-63.

Siegel, J. J. (2008). Stocks for the Long Run: The Definitive Guide to Financial Market Returns and Long-Term Investment Strategies (4 ed.). McGraw-Hill.

Siegel, J. J. (2014). Stocks for the Long Run: The Definitive Guide to Financial Market Returns and Long-Term Investment Strategies (5 ed.). McGraw-Hill.

Sornette, D. (2009). Why stock markets crash: critical events in complex financial systems. Princeton University Press.

Sornette, D. and W.-X. Zhou (2002). The US 2000-2002 market descent: how much longer and deeper? Quantative Finance 2, 468-481.

Stone, D. and W. T. Ziemba (1993). Land and stock prices in Japan. Journal of Economic Perspectives (Summer), 149-165.

Swensen, D. W. (2000). Pioneering portfolio management: an unconventional approach 
to institutional investments. The Free Press.

Weigand, R. A. . and R. Irons (2007, Summer). The market p/e ratio, earnings trends, and stock return forecasts. Journal of Portfolio Management 33(4), 87-101.

Yan, W., R. Woodard, and D. Sornette (2012a). Detection of crashes and rebounds in major equity markets. International Journal of Portfolio Analysis and Management 1(1), 59-79.

Yan, W., R. Woodard, and D. Sornette (2012b). Role of diversification risk in financial bubbles. Journal of Investment Strategies 1(4), 63-83.

Yardeni, E. (1997). Fed's stock market model finds overvaluation. Technical report, US Equity Research, Deutsche Morgan Grenfell.

Ziemba, R. E. S. and W. T. Ziemba (2007). Scenarios for Risk Management and Global Investment Strategies. Wiley.

Ziemba, W. T. (2003). The stochastic programming approach to asset liability and wealth management. AIMR, Charlottesville, VA.

Ziemba, W. T. and S. L. Schwartz (1991). Invest Japan. Probus, Chicago.

Ziemba, W. T. and S. L. Schwartz (1992). Power Japan. Probus, Chicago. 

and Political Science Houghton Street London WC2A 2AE United Kingdom 